\title{
RursuSpicae
}

Transmission, réception et réécriture de textes, de I'Antiquité au Moyen Âge

$2 \mid 2019$

Le Physiologus. Manuscrits anciens et tradition médiévale

\section{Il Physiologus nel Liber de natura rerum di Tommaso di Cantimpré}

The Physiologus in Thomas de Cantimpré's Liber de Natura Rerum

Le Physiologus dans le Liber de natura rerum de Thomas de Cantimpré

\section{Mattia Cipriani}

\section{OpenEdition}

\section{Journals}

Edizione digitale

URL: http://journals.openedition.org/rursuspicae/609

DOI: 10.4000/rursuspicae.609

ISSN: 2557-8839

Editore:

Université Nice-Sophia Antipolis, IRHT - Institut de recherche et d'histoire des textes

Notizia bibliografica digitale

Mattia Cipriani, « // Physiologus nel Liber de natura rerum di Tommaso di Cantimpré », RursuSpicae [En

ligne], 2 | 2019, mis en ligne le 20 décembre 2019, consulté le 29 mars 2021. URL : http://

journals.openedition.org/rursuspicae/609; DOI : https://doi.org/10.4000/rursuspicae.609

Questo documento è stato generato automaticamente il 29 mars 2021.

RursuSpicae 


\title{
Il Physiologus nel Liber de natura rerum di Tommaso di Cantimpré
}

\author{
The Physiologus in Thomas de Cantimpré's Liber de Natura Rerum \\ Le Physiologus dans le Liber de natura rerum de Thomas de Cantimpré
}

\section{Mattia Cipriani}

$1{ }^{1}$ Fra 1225 ca. e 1260 ca., il domenicano Tommaso di Cantimpré (1201-1270/72) ha composto e revisionato in almeno cinque occasioni il suo Liber de natura rerum (d'ora in poi: $L d n r)^{2}$. Per realizzare questo ampio trattato sulla natura, egli ha ricopiato più di 130 auctoritates eterogenee, fra cui si possono trovare i testi zoologici di Aristotele, le enciclopedie di Isidoro e Plinio, i trattati storiografici di Nennio, il cosidetto "Ps.Apuleius Complex", e le opere mediche dei salernitani Cofone, Bartolomeo, Arcimatteo e Ferrario. Tali testi sono stati ricombinati coerentemente e con intelligenza per fornire una descrizione dell'Universo introduttiva ma perfettamente funzionale ad una precisa educazione dei Predicatori e del loro pubblico ${ }^{3}$.

2 Nonostante questa grande varietà di auctoritates e i diversi modi in cui sono state impiegate - esse sono infatti state ricopiate per esteso o menzionate en passant, parafrasate o riprese alla lettera, introdotte anonimamente o accompagnate da un esplicito marker di citazione -, già nel Prologus dell'opera il brabantino ha elencato le principali basi delle sue conoscenze naturalistiche, ovvero Agostino, Aristotele, Plinio, Solino, Ambrogio, Basilio, Isidoro, Giacomo da Vitry, l'anonimo liber rerum, il misterioso Experimentator, Palladio ${ }^{4}$, Galeno, Plateario, il Physiologus e Aldelmo ${ }^{5}$ : così facendo, tali auctoritates sono state presentate come i nuclei attorno al quale è stato composto il Ldnr.

Il presente saggio si propone quindi il duplice obiettivo di (1) analizzare come e quanto il frate di Cantimpré ha ricopiato, introdotto e impiegato nella sua enciclopedia una di queste fonti - il Physiologus -, e (2) indagare quale versione di tale trattatello didattico era sul suo tavolo di lavoro durante la stesura del Ldnr. 


\section{Physiologus nel Liber de natura rerum}

4 Esaminando il ruolo che il trattatello didattico ha svolto nell'economia dell'opera tommasiana, è doveroso sottolineare subito che la sua funzione è decisamente più limitata di quanto ci si potrebbe aspettare da un testo menzionato nel Prologus dell'opera $^{6}$. Tale affermazioni deriva dall'analisi di un indicatore oggettivo e preciso, ovvero quanto il Physiologus è effettivamente stato impiegato dal domenicano.

5 Per quello che riguarda quindi il numero di excerpta usati, si può constatare che il frate di Cantimpré ne introduce solo 23 ; queste sezioni - spezzettate e ricombinate fra di loro / con altre fonti ${ }^{7}$ - sono ricavate da 19 capitoli del testo tardo-antico e vengono utilizzate unicamente per formare 23 passaggi in 20 capitoli del $L d n r^{8}$ : l'excerpta dedicato all'albero peredixion è infatti usato dal brabantino sia per questa pianta che per la voce sulla colomba9. Quanto all'effettiva lunghezza di tali excerpta, sono relativamente fedeli, e consistono soprattutto in brevi frasi semplici o in corte proposizioni complesse formate da una principle e poche subordinate ${ }^{10}$; solo in De calopo, De serra maiori e De peredixion ${ }^{11}$, l'auctoritas di origine alessandrina è inoltre usata dal frate di Cantimpré come base unica del capitolo.

6 I dati appena mostrati risultano ancora più scarni se si considera che le versioni del trattatello didattico più comuni all'epoca tommasiana erano composte da un numero di capitoli compreso fra 26 e 226 , e si può di conseguenza notare come il frate di Cantimpré ne impieghi solo una piccola porzione.

Un secondo elemento che fa risaltare la brevità dei passaggi del Physiologus nel Ldnr, deriva dalla considerazione che, ricopiando opere-base come il De animalibus di Aristotele, le Etymologie di Isidoro e la Naturalis historia di Plinio, il brabantino ne ricava rispettivamente 329, 239 e 433 sezioni, ovvero una quantità molto superiore a quella derivata dal trattatello didattico ${ }^{12}$. Un'idea analoga risulta anche dalla comparazione con fonti che, per estensione, sono più simili al Physiologus delle corpose opere appena menzionate, ovvero il De lapidibus di Marbodo, l'Imago mundi di Onorio di Ratisbona e il De febribus di Ferrario : benché tali testi non vengano né elencati da Tommaso fra le opere-base, né menzionati al momento del loro utilizzo, essi sono tuttavia più usati del trattatello didattico, con il frate di Cantimpré che ne ricava rispettivamente 56, 46 e 19 sezioni ${ }^{13}$. Sulla base di tali informazioni si può inoltre constatare che (1) la quantità di excerpta ricopiata dal Physiologus è analoga a quella derivata dalle opere di Beda ${ }^{14}$, e (2) i dati del trattatello tardo-antico sono più dei complementi ai contenuti-nucleo che vere informazioni-base per l'enciclopedia ${ }^{15}$.

8 Prima di procedere è infine possibile evidenziare un ultimo carattere che sottolinea ancora il ruolo secondario del Physiologus nell'economia del Ldnr: a differenza di auctoritates centrali come Aristotele, Adelardo di Bath, Plinio o Sesto Placito Papiriense, il trattatello è infatti impiegato da Tommaso solo nella prima redazione dell'opera e mai nelle sue numerose fasi di espansione e rimaneggiamento ${ }^{16}$.

9 Nonostante quanto detto, si ha tuttavia un elemento che giustifica la menzione del Physiologus fra le opere-base del Liber. Osservando infatti dove il frate di Cantimpré ne inserisce gli excerpta, è possibile constatare che vengono combinati quasi esclusivamente con quelli delle altre auctoritates basilari, ovvero Plinio (in 10 momenti), Isidoro (in 7), Giacomo da Vitry ed Experimentator (in 5), Ambrogio e Solino (in 3), Aldelmo (in 2), Aristotele e Basilio (in 1), e, solo in rarissimi casi, con moralizzazioni, 
informazioni originali e autori / opere secondari quali Aimone di Halbertstadt, o - nelle espansioni verso Thomas II - le questiones salernitane ${ }^{17}$. Assemblando in questo modo precise informazioni zoologiche ricavate dalle fonti-base, il domenicano ottiene comunque il duplice risultato di fornire spiegazioni precise, dettagliate e articolate su un determinato animale, ma anche, contemporaneamente, di supportare tali nozioni con le prestigiose parole di autori che - agli occhi di un uomo del XIII sec. - erano scientificamente incontestabili. Nonostante quanto detto, il brabantino salta inoltre fra un ampio range di capitoli del Physiologus, e sembra quindi corretto pensare che abbia usato l'opera di prima mano piuttosto che tramite qualche testo che ne incorporava i passaggi come il Glossarium Ansileubi ${ }^{18}$.

10 Considerando a questo punto come e perché l'operetta è usata, è possible far notare che viene spogliata da qualsiasi elemento morale, allegorico o simbolico, ed è ripresa solo nella tradizione testuale di trattati naturalistici "concreti". Tale dato è ancora più evidente se si osserva che Tommaso sostituisce sempre le sezioni simbolico-allegoriche del Physiologus con corrispettivi passaggi personali ${ }^{19}$. In questo modo le informazioni derivate dal trattatello vengono impiegate per (1) fornire dati etologici sugli animali considerati (il coraggio "auto-distruttivo" del castoro, la mansuetudine "profumata" della pantera, la prudenza della folaga, la generosità dell'upupa,.$\left.^{20}\right),(2)$ descriverne $\mathrm{i}$ caratteri fisici (i piedi dello struzzo, le sembianze della vipera,... ${ }^{21}$ ), e, infine, (3) approfondirne gli aspetti storiografici, geografici e folklorici (le esposizioni palatine di unicorni, l'habitat "regale" del caladrio, le usanze della città di Eliopoli, l'aspetto generale dell'albero peredixion e il suo rapporto con la colomba ${ }^{22}$ ). Tutti gli excerpta che il brabantino ne ricava tralasciano inoltre i contenuti mineralogico (lapides ginifera, adamas, margarita,...) dell'auctoritas didattica, ne riportano solo i contenuti zoologici e botanici, e risultano di conseguenza concentrati unicamente nei libri su animali (libri IV-IX) e - in un unico caso - piante (libro X).

11 Prima di proseguire, è ora necessario esaminare un particolare errore che Tommaso compie solo riprendendo il trattatello didattico. Osservando il modus scribendi del frate, si può notare che egli preferisce non citare le fonti usate : nonostante ciò, quando lo ritiene necessario egli le nomina (1) con le formule "ut dicit" / "sicut dicit" / "dicit" / "secundum" / "refert" seguite o precedute dal nome dell'auctoritas ricopiata ("ut dicit Isidorus", "sicut dicit Plinius", "Basilius dicit", "secundum Aristotiles", "refert Ambrosius",...), o (2) tramite il solo nome dell'autore / titolo dell'opera ricopiata ("Iacobus", "Experimentator", "Historia Persarum",... $)^{23}$. In questi momenti il domenicano è inoltre estremamente attento nell'attribuzione dei marker di citazione, e ne sbaglia di conseguenza l'assegnazione solo in pochissimi casi ${ }^{24}$. Tornando quindi alla particolarità nel rapporto fra Ldnr e Physiologus, quanto appena detto non è applicabile con i passaggi di tale fonte : escludendo la lista iniziale, infatti, in 5 casi il frate nomina tale fonte con le formule "ut dicit Physiologus" e "Physiologus" 25 , in 6 momenti la usa in modo anonimo ${ }^{26}$, ma, soprattutto, in 9 occasioni egli attribuisce ad "Ysidorus" excerpta copiati invece dal trattatello ${ }^{27}$. Sebbene non sia possibile escludere completamente che il brabantino abbia usato una copia delle Etymologie che incorporava questi passaggi ${ }^{28}$, tale ipotesi sembra tuttavia remota: se così fosse, il già scarso uso del Physiologus sarebbe infatti circoscritto a 11 casi, e ciò sembra francamente troppo limitato per un'opera che - va ricordato - è comunque specificatamente elencata da Tommaso fra i suoi testi-base. A sostegno della nostra idea va inoltre sottolineato che i 9 excerpta ascritti erroneamente ad "Ysidorus" (1) non vengono riportati in nessuna dei manoscritti e delle edizioni dell'enciclopedia isidoriana visti ${ }^{29}$, e, soprattutto, (2) 
ripropongono de verbum ad verbum il testo del Physiologus ${ }^{30}$. Come vedremo, la soluzione del problema non va quindi ricercata nel rapporto fra Pysiologus-Isidoro-Tommaso, ma piuttosto altrove.

\section{Physiologus sulla scrivania di Tommaso}

12 Come è ben noto, il Physiologus circolò nell'Europa medievale in numerose versioni più o meno "pure" : sebbene mantenessero un nucleo di contenuti relativamente costante, esse si distinguevano per struttura fluttuante, numero di capitoli variabile e differenti fonti di espansione ${ }^{31}$. A partire dal XII sec., a queste redazioni latine si aggiunsero inoltre moltissimi rimaneggiamenti volgari : tali opere non solo tradussero in anglonormanno, lingua d'oil, lingua d'oc, italiano, islandese,... una o l'altra versione del trattatello didattico, ma ne parafrasarono e fusero i contenuti in testi diversi ed innovativi. Per capire come il frate di Cantimpré si è mosso in questo crogiuolo letterario, è stato quindi necessario comparare i dati del Liber con quelli dei Physiologus che si potevano più facilmente reperire nelle biblioteche della "regione tommasiana" (gli attuali Nord-Francia, Piccardia, Belgio / Paesi Bassi) durante il periodo di stesura di Thomas I (1225 ca.-124232). In tale confronto sono state così considerate sia le redazioni latine più diffuse (Physiologus Y, C, B, A, Dicta Chrysostomi, bestiari "di prima famiglia" / BIs, Physiologus Theobaldi, bestiari H-BIs, Aviarium di Ugo di Fouilloy, bestiari "di seconda famiglia", "di transizione", $\mathrm{H}$ e "di terza famiglia"33), sia i rimaneggiamenti in piccardo e anglo-normanno del trattatello didattico (i bestiari di Pietro di Beauvais, Filippo di Thaon, Gervasio e Guglielmo il Chierico ${ }^{34}$ ). La scelta di analizzare anche questi rifacimenti volgari è motivata dal fatto che, in un paragrafo anonimo sul berillio, Tommaso riporta elementi estremamente simili al Bestiaire di Filippo di Thaon : in altre parole, sebbene il frate sembri impiegare principalmente auctoritates latine, non si può escludere a priori che egli abbia impiegato una qualche versione volgare del Physiologus ${ }^{35}$. Quanto ai criteri usati per le varie comparazioni, sono state considerati (1) i contenuti "macro-", ovvero i capitoli effettivamente presenti nelle varie redazioni del trattatello tardo-antico, e (2) quelli "micro-", e cioé le informazioni, i particolari e il lessico (nomi, verbi, aggettivi, espressioni,...) che il brabantino, visto il suo peculiare modus scribendi, ha fedelmente copiato dal trattatello in suo possesso.

Osservando innanzitutto i "macro-" contenuti di Physiologus e bestiari, si possono subito depennare dalla lista delle possibili fonti tommasiane la versio $C$, il Physiologus Theobaldi e il Bestiaire di Gervaise, in quanto omettono sempre buona parte del materiale presente invece nel trattatello sulla scrivania del domenicano: la versio $C$ è infatti priva di almeno 9 capitoli del Liber, il Physiologus Theobaldi di ben $14^{36} \mathrm{e}$ il Bestiaire di Gervasio di 7. Un discorso molto simile va fatto anche per l'Aviarium di Ugo di Fouilloy : vista la sua natura ornitologica, tale testo riporta infatti solo 3 degli animali che Tommaso ricava dal suo Physiologus, ovvero fenice, upupa e struzzo. In De garrulo, De nicticorace e De pellicano, l'opera del chierico francese viene inoltre usato dal brabantino con il proprio marker "Philosophus" o anonimamente, e anche per questo motivo non può di conseguenza coincidere con il Physiologus tommasiano ${ }^{37}$.

14 Esaminando in secondo luogo i "micro-" contenuti di Liber e rimanenti versioni del Physiologus, è possibile invece escludere che il domenicano abbia usato i Dicta Chrysostomi, e i bestiari H-BIs, "di seconda famiglia", "di transizione", $\mathrm{H}$ e "di terza famiglia". Sebbene molte di queste opere riportino spesso particolari comuni con il Physiologus di 
Tommaso $^{38}$, se ne distanziano tuttavia notevolmente per l'omissione di informazionichiave. Un esempio di tale atteggiamento si può trovare nella sezione dedicata alla fenice $^{39}$, dove il frate di Cantimpré usa il Physiologus per descrivere la città sacra di Eliopoli, l'arrivo del volatile in aprile, i preparativi che vengono allestiti per la sua morte e il ruolo svolto dai sacerdoti nella rinascita della creatura ${ }^{40}$. Tali informazioni sono tuttavia molto diverse nei Dicta, e nei bestiari H-BIs, "di seconda famiglia" e "di transizione", che si differenziano dal testo del domenicano perché non menzionano mai la città d'Egitto, sostengono implicitamente che la fenice svolge tutto senza l'aiuto di officianti e, in alcuni casi, collocano in marzo il rituale di morte-rinascita dell'uccello ${ }^{41}$. Per quanto riguarda infine i bestiari $H$ e "di terza famiglia", non solo contengono molti più dati (nomi, particolari fisici,...) del $L d n r$, ma omettono anche, rispettivamente, tutte le sezioni su fenice e albero peredixion ${ }^{42}$.

Gli stessi risultati si ottengono con le opere volgari di Filippo, Guglielmo e Pietro. Sebbene - ad eccezione del capitolo sulla vipera - i loro "macro-" contenuti corrispondano abbastanza bene a quelli del Physiologus tommasiano, anche queste rielaborazioni se ne distaccano tuttavia nei particolari contenutistico-linguistici. Per quanto riguarda il Bestiaire del poeta di Thaon, un'importante differenza con il $L d n r$ si ha nel lemma sull'unicorno : al contrario del Physiologus di Tommaso, il testo di Filippo non menziona infatti l'esposizione della bestia dopo la sua cattura, ma parla solo della sua uccisione o di un generico "farne ciò che si vuole"43. Considerando invece l'opera di Guglielmo, essa omette la descrizione del centauro, abbinata dai vari Physiologus alla sirena ${ }^{44} \mathrm{e}$ ben presente nella fonte del domenicano. Per quello che concerne infine il Bestiaire breve di Pietro di Beauvais ${ }^{45}$, esso si distanzia ad esempio dal Liber per la già citata descrizione della fenice : al pari dei testi latini discussi, anche quest'opera non menziona infatti Eliopoli e i sacerdoti egizi, ma parla solo di "legno del Libano" ${ }^{46}$. Una seconda, importante differenza fra tutti questi poemi e la fonte di Tommaso si ha poi nelle espressioni usate per l'airone : sebbene le locuzioni latine del domenicano e quelle volgari di Filippo, Guglielmo e Pietro abbiano significati analoghi, le parole del Physiologus del frate sono esattamente uguali a quelle di molte redazioni latine del trattatello, e si può di conseguenza sostenere che egli non abbia ri-tradotto in latino $\mathrm{i}$ passaggi volgari ${ }^{47}$. Sulla base di quanto detto si può infine anche affermare che le similitudini fra $L d n r$ e Bestiaire vari derivino dal fatto che tutti i loro autori erano attivi nella stessa regione e dovevano di conseguenza aver usato simili versioni del Physiologus ${ }^{48}$.

Per quanto riguarda infine $Y, B, A$ e $B I s$, nemmeno queste versioni riportano tutte le voci dell'auctoritas del brabantino. $Y$ e A hanno infatti il capitolo sulla vipera, ma difettano - rispettivamente - delle voci su struzzo e di quelle su ibis, aspidochelone e mangusta ; quanto a $B$ e BIs, riportano queste ultime sezioni ma mancano del passaggio erpetologico. Nonostante tali omissioni, a livello di particolari linguistico-contenutistici queste redazioni sono comunque le più simili alla fonte del $L d n r^{49}$, e vanno di conseguenza analizzate con attenzione. Osservando innanzitutto $Y$, essa è, fra le rimanenti, la versione più distante dalla fonte del brabantino. Come è ad esempio visibile nei passaggi su antilope, capra selvatica, pantera e folaga, essa tende infatti ad usare per le sue spiegazioni sinonimi dei termini impiegati nel $L d n r^{50}$, e si può di conseguenza depennare dalla lista delle possibili fonti tommasiane. Un discorso analogo si può fare per $A$ : sebbene a volte si avvicini linguisticamente a $B$ / BIs o al $L d n r^{51}$, tale redazione non può essere la fonte del frate di Cantimpré perché è comunque molto più simile a $Y$ che al Physiologus del domenicano. Ciò è ben esemplificato nella 
descrizione del peredixion: indicandone il moto dell'ombra, A e $Y$ usano infatti le espressioni "oriente-occidente" e "occidente-oriente", mentre BIs e la fonte tommasiana riportano più semplicemente "sinistra-destra" e "destra-sinistra" ${ }^{52}$. Per quanto riguarda infine $B$ e BIs, esse sono chiaramente le più simili a alla fonte del brabantino. Ciò è di nuovo ben visibile nei passaggi su antilope, capra, pantera e folaga, dove il linguaggio delle due redazioni e quello tommasiano coincidono perfettamente ${ }^{53}$. Nonostante l'evidente analogia, il $L d n r$ fluttua tuttavia molto spesso fra il testo di $B$ e quello di BIs, e non è quindi possibile dimostrare con assoluta certezza quale sia stata la versione impiegata dal brabantino. Tale atteggiamento è ben esemplificato dalle voci su castoro, caladrio e struzzo : le prime due impiegano infatti verbi, particolari medici ed espressioni presenti solo in $B I s^{54}$, mentre la terza riporta una citazione del Libro di Geremia contenuta unicamente in $B^{55}$. A prescindere da tale incertezza, una possibile soluzione al problema viene comunque dall'osservazione di BIs; se - come vedremo - si considera infatti che il domenicano a volte riprende brevi excerpta delle sue fonti di seconda o terza mano, sembra alquanto strano che egli non ricopi nessuno degli excerpta isidoriani inseriti nei bestiari "di prima famiglia" ${ }^{56}$, e si può quindi sostenere che abbia avuto sul suo tavolo di lavoro una versione del Physiologus senza le aggiunte dalle Etymologie. Quanto appena detto è inoltre utile per definire ulteriormente la già discussa confusione nei marker di citazione "Physiologus" / "Ysidorus": mancando un rapporto fra Physiologus del Ldnr ed Etymologie di BIs, si può anche escludere che il frate abbia usato il marker "Ysidorus" per gli excerpta del sivigliano indirettamente ricavati da un Physiologus ampliato.

Un'altra ipotesi da considerare è, a questo punto, che Tommaso abbia ripreso i suoi richiami al Physiologus indirettamente, ovvero tramite qualche altra opera che ne conteneva già i passaggi. Come anticipato brevemente sopra, tale atteggiamento non è infatti del tutto estraneo al frate di Cantimpré, che lo attua sia per auctoritates secondarie che per autori principali. La prima tipologia di queste citazioni - più comune - è composta soprattutto dagli excerpta di autori e poeti romani (Fulgenzio Mitografo, Giovenale, Marziale, Virgilio,...). In tale categoria si possono però inserire anche gli isolati rimandi al Canon di Avicenna, ad alcune opere di Costantino l'Africano e al De naturis et virtutibus aquarum di Dioscoride Pedanio. A differenza dei richiami ai testi poetici - di cui è indicato con precisione l'autore e che sono copiati sempre da Isidoro o Experimentator - questi ultimi passaggi medicali sono però anonimi, o, al massimo, segnalati con marker generici (phisicus, philosophus,...), e sembrano di conseguenza essere stati introdotti tramite opere antologiche (florilegi, epitomi,...) che già ne inglobavano i contenuti. Per quanto riguarda invece il secondo tipo di richiami indiretti, ovvero quello di auctoritates principali, sembra essere limitato ad un corto passaggio di Agostino ripreso da Michele Scoto e ad alcune frasi di Isidoro già in Experimentator. A prescindere da quanto detto e dalla loro estensione nell'opera di origine, tutto questo particolare atteggiamento tommasiano è inoltre caratterizzato da due elementi precisi. Innanzitutto è estremamente sporadico, con solo 20 excerpta di questo genere in tutta l'enciclopedia domenicana. In secondo luogo, i passi ricavati in tale maniera sono estremamente brevi, ovvero composti da una o, al massimo - e molto raramente - due corte frasi. L'atteggiamento che il brabantino ha con il Physiologus è, quindi, chiaramente differente. Benché anche gli excerpta derivati da questo trattatello siano pochi e brevi se confrontati con quelli ricavati da Plinio o Aristotele, essi sono comunque sempre più numerosi, lunghi e consistenti di quelli introdotti di seconda o terza mano. Di conseguenza, sebbene non possibile escludere completamente l'ipotesi 
di una ripresa indiretta del Physiologus, tale idea sembra estremamente remota, e sarebbe - va detto chiaramente - un unicum per le opere che Tommaso indica come basi delle sue conoscenze naturalistiche ${ }^{57}$.

Prima di concludere, è quindi necessario aggiungere qualche ulteriore considerazione sul testo a disposizione del frate di Cantimpré. Benché, come si è detto, la fonte di Tommaso riporti quasi sempre particolari linguistico-stilistici più vicini a $B / B I s$ che a $Y$ ed $A$, essa si discosta da questa linea generale in tre momenti, ovvero con l'introduzione del capitolo sulla vipera, nella discussione sull'aspidochelone e in quella sul pesce sega. Considerando il passaggio erpetologico, è doveroso ricordare di nuovo che manca nelle versioni $B$ e BIs giunte sino a noi, ma si trova invece in $Y$ ed $A$. Per quello che riguarda la sezione sul cetaceo-isola, parlando di fuochi accesi, ancore scagliate e immersione della bestia fra i flutti, il testo del brabantino usa termini propri solo a $Y$, e non quelli che tale redazione condivide con $B, A$ e BIs, o quelli unici a tali versioni, e si può di conseguenza affermare che la versio antica si colloca in questa occasione a metà strada fra la fonte tommasiana e il gruppo $B, A$ e $B I s^{58}$. Per quanto concerne il passaggio sul pesce serra, tutto ciò risulta invece invertito, ed è l'enciclopedia del brabantino che sembra fondere le locuzioni di $Y$ con il testo delle altre versioni latine rimanenti ${ }^{59}$. Ad ogni modo, sebbene non sia possibile escludere completamente che il frate di Cantimpré abbia usato contemporaneamente una copia $Y$ e una $B$ del trattatello didattico, tale ipotesi sembra tuttavia remota : è infatti illogico che Tommaso si sia rifatto alla più breve versio $B$ per quasi tutte le sue citazioni del Physiologus, ma abbia poi ripreso una più ampia $Y$ solo per aggiungere il capitolo sulla vipera, e alcuni particolari su balena-isola e pesce sega.

\section{Conclusioni}

19 Per terminare la nostra analisi, è ora utile tornare su alcuni punti lasciati volontariamente in sospeso, ovvero (1) le motivazioni per cui Tommaso impiega gli excerpta del Physiologus in maniera limitata, (2) le cause dell'esclusivo errore di citazione compiuto con tale trattatello, e (3) la tipologia testuale della fonte tommasiana.

Esaminando innanzitutto le ragioni che hanno spinto il frate di Cantimpré ad usare il Physiologus in maniera contenuta, una spiegazione di questo comportamento è rintracciabile già nella lista delle principali auctoritates del Lndr. Nonostante il brabantino inserisca il trattatello nel suo elenco introduttivo, tale auctoritas è l'unica, fra le fonti-base, ad essere presentata da Tommaso con un certo distacco : se Agostino viene infatti definito "dottore incomparabile", Galeno e Plateario sono indicati come eccellenti autori medico-botanici, e Aldelmo è qualificato come un sapiente che scrive poco ma benissimo ${ }^{60}$, il breve testo didattico viene al contrario descritto solamente come un'opera "abbastanza valida e utile" ${ }^{11}$. In altre parole, non sembra scorretto sostenere che il domenicano abbia usato il Physiologus in maniera limitata perché ne riteneva in realtà i contenuti poco convincenti rispetto a quelli di altre auctoritates "più moderne".

21 Considerando in secondo luogo l'attribuzione scorretta di molti passaggi derivati dall'operetta, è doveroso ribadire che non c'è nessun legame fra gli excerpta di quest'opera che il Ldnr lega erroneamente ad Isidoro, le Etymologie che circolavano al tempo del brabantino e quelle sui generis inserite nei bestiari "di prima famiglia". La soluzione del problema di Tommaso va quindi ricercata altrove, ovvero nelle fasi di 
trasmissione del Liber e nella grafia / abbreviature del '200. Come è ben esemplificato anche in uno dei testimoni più antichi di Thomas I - il manoscritto Bonn, Universitätsbibliothek, S $487^{62}$ - (1) le abbreviature "Ph'iologus " o "Ph's" usate per il trattatello didattico fondono spesso le lettere ' $P h$ ' in una sorta di ' $y$ ' e, quando presente, la sillaba 'ol' in una 'd', e (2) le sigle "ysi" / "ýsi" e "ysid" / "ýsid" impiegate per l'autore delle Etymologie mostrano invece una ' $y$ ' estremamente inclinata che diventa simile ad una ' $p$ '63. Secondo quanto appena detto, l'errata assegnazione del marker "Ysidorus" / "Physiologus" potrebbe quindi essere dovuta ad una fusione / confusione paleografica fra i rimandi "(ph)iol[ogus]" e "(ys)id[orus]". Vista la diffusione di questo comportamento in tutti i testimoni conosciuti del $L d n r$, è inoltre possibile ritenere che tale confusione sia stata fatta o già da Tommaso nei suoi appunti preparatori al Liber, o da uno dei primissimi copisti dell'opera. Per rafforzare questa ipotesi è infine utile esaminare rapidamente la citazione del passaggio sull'upupa ${ }^{64}$. A prescindere dalla loro fase di stesura, solo una parte dei testimoni del $L d n r$ attribuisce infatti correttamente l'excerpta sul volatile al Physiologus, mentre altri ne sbrogliano impropriamente l'abbreviatura nel più generico "Phylosophus" ${ }^{5}$. Sulla base di quanto appena mostrato, si può quindi notare che una generale confusione legata al marker "Physiologus" sia stata qualcosa di reale e ben presente in tutta la tradizione più antica del Ldnr, e l'ipotesi di un errore paleografico è quindi un elemento concreto e reale.

Per quanto concerne infine il tipo di Physiologus sulla scrivania tommasiana, è possibile sottolineare che - viste le caratteristiche precedentemente evidenziate - non doveva trattarsi di una versio $B$ canonica, ma, piuttosto, di un ibrido $B-Y$ "tendente a" BIs. Questo Physiologus "intermedio" doveva tuttavia essere diverso degli "ibridi" riportati nei codici London, British Library, Royal 6 A XI, e Lyon, Bibliothèque municipale, 125. Al contrario delle versioni presente in questi manoscritti, la fonte tommasiana doveva infatti avere elementi testuali più simile $\mathrm{a} B$ che $\mathrm{Y} Y$, ma doveva anche presentare anche caratteri stilistici, singoli particolari ed almeno un intero capitolo derivati da $Y$. La "base B" che ne rappresentava il nucleo si doveva inoltre avvicinare più al Physiologus usato per BIs che a quello "puro" edito da Carmody.

In conclusione, sebbene non sia stato possibile trovare una copia di tale opera, sembra interessante osservare il manoscritto Montecassino, Archivio dell'Abbazia, 323: il Physiologus versio B riportato in questo codice, infatti, (1) contiene i capitoli finali (columba, peredixion, elefans, adamas) solitamente assenti negli altri testimoni della stessa tipologia, ma presenti nei testimoni di BIs, e (2) aggiunge elementi di $Y$ (il capitolo myrmicoleon $)^{66}$. Questa redazione - che, viste le sue caratteristiche, trasmette quindi un testo $B-Y$ "tendente a" BIs - dimostra di conseguenza l'esistenza di una tipologia di Physiologus dai caratteri molto simili al testo che doveva essere stato ricopiato anche dal frate di Cantimpré.

\section{BIBLIOGRAFIA}




\section{Manoscritti consultati}

Basel, Universitätsbibliothek, F III 15

Bern, Bürgerbibliothek, 233

Bern, Bürgerbibliothek, 318

Bonn, Universitätsbibliothek, S 487

Brugge, Stadtbibliothek, 410

Bruxelles, Bibliothèque Royale, KBR 10074

Cambridge, Corpus Christi College, 22

Cambridge, Fitzwilliam Museum, 254

Chalon-sur-Saône, Bibliothèque municipale, 14

Città del Vaticano, Biblioteca Apostolica Vaticana, Pal. lat. 1074

London, British Library, Arundel 298

London, British Library, Harley 3244

London, British Library, Harley 3717

London, British Library, Royal 6.A.XI

London, British Library, Royal 12.C.XIX

London, British Library, Stowe 1067

Los Angeles, Getty Museum, 100

Montecassino, Archivio dell'Abbazia, 323

München, Bayerische Staatsbibliothek, Clm 6250

Oxford, Bodleian Library, Auct. T.2.23

Oxford, Bodleian Library, Laud Misc. 247

Paris, Bibliothèque nationale de France, Lat. 425

Paris, Bibliothèque nationale de France, Lat. 426

Paris, Bibliothèque nationale de France, Lat. 14429

Paris, Bibliothèque nationale de France, Nouv. acq. lat. 873

Rouen, Bibliothèque municipale, 638

St. Gallen, Stiftsbibliothek, Cod. Sang. 236

Stuttgart, Landesbibliothek, Cod. med. et phys. fol. 30

Wolfenbüttel, Hertzog August Bibliothek, Gud. lat. 148

Wrocław, Biblioteka uniwersytecka, Rehdig. 174

\section{Fonti}

Bestiari medievali, MORINI Luigina (dir.), Torino, 1996. 
De bestiis et aliis rebus, liber II (Bestiarius, versio H), MIGNE Jacques-Paul (ed.), (Patrologia latina cursus completus), Paris, 1844-1855, vol. 177, p. 56-83.

« Dicta Chrysostomi », vON HEIDER Gustav (ed.), (Physiologus : nach einer Handschrift des XI.

Jahrhunderts), Wien, 1851.

« Excerpta ex antiquissimo libro Physiologo », MAI Angelo (ed.), (Classici Auctores), Roma 1835, vol. 7, p. 589-596.

FERRARIUS, Curae, GIACOSA Piero (ed.), in Magistri Salernitani nondum editi, GIACOSA Piero (ed.), Turin, 1901, p. 1-68.

From the Ark to the Pulpit: an Edition and Translation of the 'Transitional' Northumberland Bestiary (13th century), wHITE Cynthia (ed.), Louvain-la-Neuve, 2009.

GERVAISE, « Le bestiaire de Gervaise », MEYER Paul (ed.), Romania 1, 1872, p. 420-443.

HUGO DE FOLIETO, Aviarium : The Medieval Book of Birds. Hugh of Fouilloy's 'Aviarium', CLARK Willene B. (ed.), New York, 1992.

ISIDORUS HISPALENSIS, Etymologiae XII : des animaux, JACQUES André (ed.), Paris, 1986.

ISIDORUS HISPALENSIS, Etymologiarum sive Originum libri XX, LINDSAY Wallace M. (ed.), Oxford, 1911, 2 voll.

ISIDORUS HISPALENSIS, Etimologías. Edición bilingüe. Texto latino, OROZ RETA José - CASQUERO Manuel-A. Marcos - DíAZ Y DíAZ Manuel C. (ed.), Madrid, 2004.

GUILlAUME LE CleRc, Le Bestiaire Divin de Guillaume Clerc de Normandie, HIPPEAu Célestin (ed.), Caen, 1852.

« Liber monstrorum », ORCHARD Andy (ed.), in ORCHARD Andy, Pride and Prodigies. Studies in the Monsters of the Beowulf-Manuscript, Toronto-Buffalo-London, 1995, p. 254-317.

« Les plus anciens lapidaires français », MEYER Paul (ed.), Romania 38, 1909, p. 539-552.

PHILIPPE DE THAON, Bestiaire, WALBERG Emmanuel (ed.), Paris, 1900.

PHILIPPE DE THAON, Bestiaire, MORINI Luigina (ed.), Paris, 2018.

PIERRE DE BEAUVAIS, Bestiaire de Pierre de Beauvais, version courte, MERMIER Guy R. (ed.), Paris,1977.

PIERRE DE BEAUVAIS, Le bestiaire : version longue attribuée à Pierre de Beauvais, BAKER Craig (ed.), Paris, 2010.

Physiologus Bernensis, voll-Faksimile aus des Codex Bongarsianus 318 der Burgerbibliothek Bern, voN STEIGER Christoph - HOMBURGER Otto (ed.), Basel, 1964.

Physiologus Latinus, versio B, CARMODY Francis J. (ed.), Paris, 1939.

«Physiologus Latinus, versio BIs », MANN Max F. (ed.), in MANN Max F. (ed.), Der 'Bestiaire Divin' des Guillaume le Clerc, Heilbronn, 1888, p. 37-73.

«Physiologus Latinus, versio Y», CARMODY Francis J. (ed.), University of California Publications in Classical Philology 12, 7, 1941 : 95-134.

THEOBALDUS, Theobaldi Physiologus, EDEN Peter T. (ed.), Leiden-Köln, 1972.

THOMAS CANTIMPRATENSIS, Liber de naturis rerum, BOESE Helmut (ed.), Berlin-New York, 1973. 
THOMAS CANTIMPRATENSIS, Liber de naturis rerum, redazioni I-II, CIPRIANI Mattia (ed.), (versione parziale ma con riscontro delle fonti aggiornato al novembre 2017; URL : http://sourcencyme.irht.cnrs.fr/ encyclopedie/voir/972 )

\section{Letteratura secondaria}

ANSPACH, August Eduard, « Das Fortleben Isidors im VII. bis IX. Jahrhundert », Miscellanea Isidoriana. Homenaje a S. Isidoro de Sevilla en el XIII Centenario de su muerte. 636 - 4 de abril - 1936, Roma, 1936, p. 323-356.

BAKER Craig, « De la paternité de la version longue du Bestiaire attribuée à Pierre de Beauvais ", Bestiaires médiévaux. Nouvelles perspectives sur les manuscrits et les traditions textuelles, VAN DEN ABEELE Baudouin (dir.), Louvain-la-Neuve, 2005, p. 1-29.

BAXTER Roland, Bestiaries and Their Users in the Middle Ages, Stroud, 1998.

BOESE Helmut, « Zur Textüberlieferung von Thomas Cantimpratensis' Liber de natura rerum », Archivum fratrum praedicatorum, 39, 1969, p. 53-68.

CAHIER Charles - MARTIN Arthur, Mélanges d'archéologie, d'histoire et de littérature, Paris, 1851, vol. $2-4$.

CARMODY Francis J., « De Bestiis et Aliis Rebus and the Latin Physiologus », Speculum, 13, 2, 1938 , p. 153-159.

CATON Fernandez, J. M., Las Etimologías en la tradición manuscrita medieval estudiada por el Dr. Anspach, León, 1966.

CIPRIANI Mattia, La place de Thomas de Cantimpré dans l'encyclopédisme médiéval : les sources du Liber de natura rerum, Tesi, Paris-Firenze, 2014, vol. 1-2.

CIPRIANI Mattia, « Un aspect de l'encyclopédisme de Thomas de Cantimpré : la section De lapidibus pretiosis du Liber de natura rerum », Médiévales 72, 2017, p. 155-174

CIPRIANI Mattia, «Questio satis iocunda est : analisi delle fonti di questiones et responsiones del Liber de natura rerum di Tommaso di Cantimpré », RursuSpicae, Primavera-Autunno 2017 (URL : http:// journals.openedition.org/rursus/1330).

CIPRIANI Mattia, «In dorso colorem habet inter viridem et ceruleum... : Liber rerum e osservazione zoologica diretta nell'enciclopedia di Tommaso di Cantimpré », Reinardus. Yearbook of the International Reynard Society, 29, 2017, p. 16-98.

CIPRIANI Mattia, «Si vero ex amore vel tristitia vel ira... : emozioni, sentimenti e stati d'animo nel Liber de natura rerum di Tommaso di Cantimprè ", in BAKER Craig - CAVAGNA Mattia - CLESSE Grégory (dir.), Entre le cour et le diaphragme. (D)écrire les émotions dans la littérature narrative et scientifique du Moyen Âge, , Louvain-la Neuve, 2018, p. 35-48.

CLARK Willene B., « Four Latin Bestiaries and De bestiis et aliis rebus », Bestiaires médiévaux..., p. 49-69.

CLARK Willene B., A Medieval Book of Beasts. The Second-Family Bestiary: Commentary, Art, Text and Translation, Woodbridge, 2006.

DINES Ilya, «The Problem of the Transitional Family of Bestiaries ", Reinardus. Yearbook of the International Reynard Society 24, 2012, p. 29-52. 
DINES Ilya, « The Earliest Use of John of Salisbury's Policraticus : Third Family Bestiaries », Viator. Medieval and Reinassance Studies 44, 1, 2013, p. 107-118.

DINES Ilya, « The Bestiary in British Library, Royal MS. 2 C. XII and its Role in Medieval Education ", Electronic British Library Journal, 2014, art. 9.

DOROFEEVA Anna, The Reception and Manuscript Context of the Early Medieval Latin Pre-Bestiary Physiologus, Tesi, Cambridge, 2015.

eVDoKimova Ludmilla, « Deux traductions du Physiologus : le sens allégorique de la nature et le sens allégorique de la Bible ", Reinardus. Yearbook of the International Reynard Society, 11, 1998, p. 53-66. HENKEL Nikolaus, Studien zum Physiologus im Mittelalter, Tübingen, 1976.

JAMES Montague R., The Bestiary, Being a Reproduction in Full of the Ms. Ii.4.26 in the University Library, Oxford, 1928.

KAIMAKIS Dimitris V., Der Physiologus nach der ersten Redaktion, Meisenheim am Glan, 1974.

KAY Sarah, « The English Bestiary, the Continental Physiologus and the Intersections Between Them », Medium Aevum 85, 1, 2016, p. 118-142.

KUHRY Emmanuelle, «Les chapitres sur les poissons et créatures aquatiques dans la tradition manuscrite du Physiologus latinus et des bestiaires latins et leur réception dans quelques encyclopédies médiévales ", in GAUVIN Brigitte- LUCAS-AVENEL Marie-Agnès (dir.), 'Inter litteras et scientias', Recueil d'études en hommage à Catherine Jacquemard, Caen, 2019, p. 117-150.

LAUCHERT Friedrich, Geschichte des Physiologus, Strassburg, 1889.

MCCULLoch Florence, Medieval Latin and French Bestiaries, Chapel Hill, 1962.

MERMIER Guy R., « De Pierre de Beauvais et particulièrement de son Bestiaire : Vers une solution des problèmes ", Romanische Forschungen, 78, 2/3, 1966, p. 338-371.

MERMIER Guy R., A Medieval Book of Beasts: Pierre de Beauvais' Bestiary, Lewiston (NY), 1992.

MORTON Jonathan, « The Book of the World at an Anglo-Norman Court : The Bestiaire de Philippe de Thaon as a Theological Performance », in ASHE Laura - LAWTON David-SCASE Wendy (dir.), New Medieval Litterature, 16, , Cambridge, 2016, p. 1-39.

MURATOVA Xénia, « Le Bestiaire médiéval et la culture normande », Manuscrits et enluminures dans le monde normand: Xe-XVe siècles : colloque de Cerisy-la-Salle, octobre 1995, Caen, 1999, p. 151-166.

OFFERMANNS Dieter, Der Physiologus nach den Handschriften G und M, Meisenheim am Glan, 1966.

OMONT Henri, Catalogue général des manuscrits des bibliothèques publiques de France. Départements : tome I : Rouen , Paris, 1886.

ORLANDI Giovanni, « La tradizione del 'Physiologus' e i prodromi nel bestiaro latino », L'uomo di fronte al mondo animale nell'alto Medioevo, 7-13 aprile 1983, Spoleto, 1985, vol. I, p. 1057-1106.

PAYNE Ann, Medieval Beasts, London, 1990.

RIBÉMONT Bernard, «L'animal comme exemple dans les encyclopédies médiévales : morale et 'naturalisme' dans le 'Livre des propriétés des choses' ", L'animal exemplaire au Moyen Âge, $V^{e}-X V^{e}$ siècles, BERLIOZ Jacques, POLO DE BEAULIEU Marie-Anne (ed.), Rennes, 1999, p. 191-205.

ROBERT Ulysse, Catalogue général des manuscrits des bibliothèques publiques de France. Départements : tome XXX : Lyon, Paris, 1900. 
SBORDONE Francesco, « La tradizione manoscritta del Physiologus latino », Athenaeum, 27, 1949 : 246-280.

SILVESTRE Hubert, « A propos du Bruxellensis 10066-77 et de son noyau primitif », Miscellanea codicologica F. Masai dicata, Cockshaw Pierre (dir.), 1979, p. 131-156.

SMEETS J. R., «L'Ordre des Animaux dans le Physiologus de Philippe de Thaon et la prétendue préséance de la perdrix sur l'aigle ", Revue Belge de Philologie et d'Histoire / Belgisch Tijdschrift voor Filologie en Geschiedenis, 40, 1962, p. 798-803.

STEWART Patricia, The Medieval Bestiary and Its Textual Tradition, Tesi, Saint-Andrews, 2012, 2 voll. VAN DEN ABEELE Baudouin, « L'allégorie animale dans les encyclopédies latines du Moyen Âge », L'animal exemplaire, 1999, p. 123-143.

VAN DEN ABEELE Baudouin, « Un Bestiaire latin à la croisée des genres: le manuscrit Cambridge UL Gg.6.5 ('quatrième famille' du Bestiaire latin) », Reinardus. Yearbook of the International Reynard Society, 13, 2000, p. 215-236.

VAN DEN ABEELE Baudouin, « Deux manuscrits inconnus du Bestiaire attribué à Pierre de Beauvais ", Bestiaires médiévaux..., p. 183-199

VAN DEN ABEELE Baudouin, « Diffusion et avatars d'une encyclopédie : le Liber de natura rerum de Thomas de Cantimpré », in DE CALLATAŸ Godefroid - B. VAN DEN ABEELE Baudouin (dir.), Une lumière venue d'ailleurs, Turnhout, 2008, p. 141-176.

VAN DEN ABEELE Baudouin, « La tradition manuscrite des Etymologies d'Isidore de Séville », in ELFASSI Jacques -RIBÉMONT Bernard (dir.), La réception d'Isidore de Séville durant le Moyen Âge tardif (XII $e^{e} X V^{e}$ s.), Paris, 2008, p. 195-208.

VOLLMANN Benedikt K., « La vitalità delle enciclopedie di scienza naturale », in PICONE Michelangelo (dir.), L'enciclopedismo medievale, Ravenna, 1994, p. 135-146.

VOLLMANN Benedikt K. $(\dagger)$ - DÉUS Janine - WEIGAND Rudolf K. - ULMSCHNEIDER Helgard (ed.), Thomas von Cantimpré, Liber de naturis rerum: Kritische Ausgabe der Redaktion III (Thomas III) eines Anonymus, Wiesbaden, 2017.

YAPP Brunsdon, «A New Look at English Bestiaries », Medium Aevum, 54, 1985 : 1-19.

\section{ALLEGATO}

\section{Tabella 1 : "macro-" contenuti Ldnr / Physiologus}

La tabella mette a confronto i capitoli del Ldnr in cui è usato il Physiologus con quelli effettivamente presenti nelle versioni conosciute di tale opera ; con la " $x$ " si indica una corrispondenza fra i testi considerati, con "/" viene invece rimarcata l'assenza di un capitolo. 


\section{Tabella 2 : Corrispondenze testuali fra Ldnr e Physiologus versio $B$ / A / versioni ibride / B/s ${ }^{67}$}

La tabella confronta il testo che Tommaso ricava dal Physiologus con quello delle varie redazioni del trattatello. Al termine di questi ultimi passaggi viene indicata la versione del testo ricopiata e la pagina / il foglio in cui è possibile trovare tale paragrafo ${ }^{68}$; quando un capitolo è assente, è stato indicato con "manca" seguito - quando ritenuto necessario - da eventuali spiegazioni.

\section{Castor}

Ldnr, 4.14, De castoribus qui fibri dicuntur : Quibus venator collectis, feram abire permittit. Quod si ab aliis venatoribus postea fuerit insecutus, evadendi desperatione fractus erigit se, et, se amputatos, ostendit testiculos venatori.

$Y$ : Uenator autem currens, ut eum consequatur in montibus, castor autem uidens uenatorem persequentem, se ore suo incidit uirilia sua, et dat uenatori proiciens. Si autem alius uenator eum persecutus postea fuerit, proicit se supinum, et ostendit se uenatori; et uenator uidens se non habere uirilia, discedit ab eo (ed. CARMODY : 128-129).

B : Venator autem veniens colligit eos, et ultra iam non persequitur eum, sed recedit. Si autem rursus evenerit ut alter venator perquirens inveniat et sequatur post eum, ille videns se iam evadere non posse, erigit se et demonstrat virilia sua venatori (ed. CARMODY : 32-33).

A : Venator autem veniens colligit eos, et ultra iam non persequitur, si vero rursus evenerit ut alter venator perquirens et ${ }^{69}$ inveniat et persequitur eum, ille erigit eum, ille videns se iam evadere non posse, erigit ${ }^{70}$ se et demonstrat virilia sua venatori (ed. CAHIER-MARTIN, II :

117-118).

Lyon, B.M., 125 : Venator enim veniens colligit eos, et ultra iam non sequitur eum, sed recedunt ab eo. Si enim rursus evenerit ut alter venator perquirens inveniat et persequitur eum, ille videns se evadere non posse, erigit se et demonstrat virilia sua venatori (192r-192v).

London, B.L., Royal 6.A.XI : Venator veniens colligit eos, et ultra iam non persequitur eum, sed autem rursus venator persequitur eum, erigit se et ostendit virilia sua quia videt (146r).

Bis : Venator veniens colligit eos, et ultra iam non sequitur eum, sed revertitur. Si vero rursus contigerit ut alter venator eum prosequatur, ille videns evadere non posse, erigit se et ostendit virilia sua venatori (ed. MANN : 50-51).

\section{Calopus}

Ldnr, 4.16, De calopo : Calopus, ut Physiologus dicit, animal acerrimum est, ita ut nec a venatoribus possit appropinquari. Cornua longa habet, serre figuram habentia, ita ut possit altas arbores secando deicere. Cum sitit, ad flumen Eufratem bibit. Est autem ibi frutex herychyna virgultis subtilibus et prolixis. Cui dum adveniens cornibus alludit, ipsa cornua obligat in virgultis, pugnansque diu nec liberare se valens exclamat horrifice. Cuius voce venator audita accurrens herentem occidit.

$Y$ [Autolops] : Est animal quod dicitur autolopus, acerrimum nimis, ut nec uenator possit ei appropinquare. Habet autem longa cornua serre figuram habentia, ut possit precidere arbores 
magnas et altas, et ad terram deponere. Si autem sitierit, uadit ad terribilem Eufraten flumen, et bibit; sunt autem ibi ricine (dicuntur grece), hoc est frutices tenues ramos habentes; et uenit ludens ad illam ricinum fruticem, et obligatur in ramis eius (ed. CARMODY : 104).

B [Autolops] : Est animal acerrimum nimis, ita ut nec uenator ei possit appropinquare. Habet autem longa conua serrae figuram habentia, ita ut possit etiam arbores altas et magnas secare et ad terram deponere. Et cum sitierit, uenit ad magnum flumen Euphratem, et bibit; est autem ibi frutex qui dicitur graece herecine, habens uirgulta subtilia atque prolixa; ueniens autem incipit ludere cornibus suis ad herecinam; et dum ludit, obligat cornua sua in uirgultis eius. Cum autem diu pugnans liberare se non possit, exclamat uoce magna; audiens autem uenator uocem eius, uenit et occidit eum (ed. CARMODY : 12).

A [Autolops]: Item est aliud animal qui dicitur autalops acerrimum, ita ut nec uenator ei possit adpropinquare. Habet autem longa conua serrae figuram habentia, ita ut possit etiam arbores altas et magnas resecare ${ }^{71}$ et ad terram deponere ${ }^{72}$. Quum autem sitierit, venit ad magnum Eufraten fluvium, et bibit. Est autem ibi frutex qui dicitur graece herecine, habens uirgulta subtilia et prolixa. Ueniens autem incipit ludere cornibus suis ad herecinam; et dum ludit, obligat cornua in uirgultis eius. Quum autem diu pugnans se liberare ${ }^{73}$ non possit, tunc exclamat uoce magna; audiens autem uenator uocem eius, et occidit eum (ed. CAHIER-MARTIN, II : 117-118).

Lyon, B.M., 125 [Serra] : Item est animal quod dicitur serra <sic > acerrimum nimis, ita ut nec uenator possit appropinquare ad eum. Habet enim conua longa serrae figuram habentia, ita ut possit arbores secare altas et magnas ${ }^{74}$ et ad terram deponere ${ }^{75}$. Cum hanc sitierit, venit ad magnum flumen Eufratem, et bibit. Est autem ibi frutex qui dicitur herecine, habens uirgulta subtilia et prolixa. Venit ergo incipit ludere cornibus suis ad erecine; et dum ludit, obligat cornua sua in uirgultis eius. Cum enim diu pugnans liberare se non possit, exclamat uoce magna; audiens autem uenator nocem eius, venit et occidit eum (189v).

London, B.L., Royal 6.A.XI [Serra] : Est animal quod dicitur serra $<$ sic $>$ acerrimum nimis, ita ut nec uenator appropinquare possit. Habet enim conua longa serre figuram habentia, ita ut possit et iam arbores altas et magnas secare et ad terram deponere ${ }^{76}$. Cum autem sitit, vadit ad flumen magnum Eufratem, et bibit. Est ibi frutex quod dicitur ericine, habens uirgulta subtilia et prolixa. Veniens enim incipit ludere ad erecinam; et dum ludit, alligat cornua sua in virgultis eius. Cum enim diu pugnans se deliberare non possit, exclamat uoce magna; audiens ergo uenator eius, venit et occidit eum (144v).

BIs [Autolops] : Est animal acerrimum nimis, ita ut nec uenator ei possit appropinquare. Habet autem longa conua serrae figuram habentia, ita ut possit etiam arbores altas et magnas secare et ad terram deponere. Et cum sitit, uenit ad magnum flumen Euphratem, et bibit; est autem ibi frutex qui dicitur graece herecine, habens uirgulta subtilia atque prolixa; ueniens autem incipit ludere cornibus suis ad herecinam; ueniens autem incipit ludere cornibus suis ad herecinam; et dum ludit, obligat cornua sua in uirgultis eius. Cum autem diu pugnans liberare se non possit, exclamat uoce magna; audiens autem uenator uocem eius, uenit et occidit eum (ed. MANN : 38-39).

\section{Capra / Hircus}

Ldnr, 4.18, De De capra vel hirco : Caper silvestris animal sagacissimum est, altos montes amat, delonge positos homines agnoscit ambulantes, si venatores aut viatores sint. 
Y : Amat satis excelsos montes, escam autem inuenit in humilia montium.Et uidet de longe omnes qui ueniunt ad eam, et cognoscit si cum dolo ueniant, uel cum amicitia (ed. CARMODY : 119).

B : De hac Phisiologus dicit quod amat altos montes, pascitur autem in convallibus montium. Est autem satis perspicuum animal et nimis de longe previdens; ita ut si viderit subito homines in alia regione ambulantes, statim cognoscat an venatores sunt, an viatores (ed. CARMODY : 36 ).

A : De hac Phisiologus dicit quod amat altos montes, pascitur in convallibus montium. Est vero satis perspicuum animal et nimis de longe providens; ita ut si viderit subito in alia regione homine ambulantes, statim agnoscit an viatores sint an venatores (ed. CAHIER-MARTIN, III : 219).

Lyon, B.M., 125 : De hac Fisiologus dicit quia amat altos montes, pascitur enim in convallibus montium. Est vero satis priscuum animal et nimis de longe previdens; omnia ita ut si viderit subito in alia regione homines ambulantes, statim agnoscit an amatores sunt, an venatores (192v).

London, B.L., Royal 6.A.XI [De animal quod dorco ${ }^{77}$ vel capra] : Hoc Phisiologus dicit quia amat altos montes, pascitur autem in convallibus montium. Est vero satis perspicuum animal et nimis de longe previdens omnia; ita ut si viderit in alia regione ambulantes, statim agnoscit an viatores sint aut venatores (141r).

BIs : De hac Phisiologus dixit quod amat altos montes, pascitur autem in convallibus montium. Est autem providum animal eminus de longe previdens; ita ut si viderit subito homines in alia regione ambulantes, statim cognoscat an venatores sunt, an viatores (ed. MANN : 53).

\section{Onager}

Ldnr, 4.80, De onagro : Hic quintodecimo die mensis Martii, ut dicit Ysidorus, duodecies in nocte rugit, totiens et in die, unde ex hoc cognoscitur quod equinoctium est. [...] Onager masculus diabolus dicitur esse.

$Y$ : Phisiologus dicit de onagro quoniam est gregis primus in eis; et si generauerit greges masculos, pater eorum confringit necessaria eorum, ut non faciant semen (ed. CARMODY : 109) [...] in quinta et uigesima Famenoth mensis cognoscunt ab onagro quoniam equitas dierum fit : si autem clamauerit duodecies, cognoscit rex et palatium quoniam equitas diei fiet. [...] Onager est diabolus (ed. CARMODY : 121).

B : Phisiologus dicit de onagro quia viscesimo quinto die mensis famenoth, qui est marcius, duodecies in nocte rugit, similiter et in die; et ex hoc cognoscitur quia equinoctium est diei, vel noctis, et numerum horarum a rugibus onagri per singulas cognoscunt horas, simul rigiens. Onager igitur figuram habet diaboli (ed. CARMODY : 37).

A : Phisiologus dicit de onagro quia viscesimo quinto die mensis famoth, qui est marcius, duodecies in nocte rugit, similiter et ex hoc agnoscitur qui[a] equinoctium est diei, vel noctis, ex ${ }^{78}$ numero horarum rugitus onagri per singulas horas, semel rugientis. Onager igitur figuram ${ }^{79}$ habet diaboli (ed. CAHIER-MARTIN, III : 225-226).

Lyon, B.M., 125 : Phisiologus dicit de onagro quia vicesima die mensis fanmoth, qui est marcius, duodecies rugit in nocte, similiter et in die; et ex hoc cognoscitur quia equinoctium est 
diei, diem autem vel noctem intelligiumus equiparari ex numero horarum vel rugitus onagri qui per singulas horas diei et noctis semel rugit. Onager qui figuram habet diaboli (193r).

London, B.L., Royal 6.A.XI : Phisiologus dicit de eo quia viscesima die mensis famino, qui est marcius, duodecies rugit in nocte, similiter et in die; et ex hoc agnoscitur quia equinoctium est numerum horarum rugitus onagri per singulas horas diei et noctis, semel rugientis ita discernit. Onager igitur figuram habet diaboli (141v).

BIs : Phisiologus dicit de onagro quia viscesimo quinto die mensis famenoth, quod est marcius, duodecies in nocte rugit, similiter et in die; et ex hoc cognoscitur qui[a] equinoctium est diei, vel noctis, et numerum horarum a rugibus onagri per singulas cognoscunt horas, semel rugientis. Onager igitur figuram habet diaboli (ed. MANN : 54).

\section{Onocentaurus}

Ldnr, 4.82, De onocentauro : Alii autem dicunt onocentaurum corpus habere equinum, superiorem vero partem humanam.

$Y$ : Similiter et onocentauri, a pectore et sursum hominis habet figuram, deorsum autem asini (ed. CARMODY : 113-114).

B : Onocentaurum duabus naturis constare Physiologus asserit, id est: superior pars hominis similis, inferioris vero partis menbra sunt nature valde agrestis (ed. CARMODY : 26).

A : Honocentaurum diaboli natura constare Physiologus asserit, id est: superior pars hominis similis, inferiora vero eius asini menbra sunt (ed. CAHIER-MARTIN, III : 173-175).

Lyon, B.M., 125 : Et honocentaurum duabus natura constare Physiologus asserit, id est: superior pars est hominis similis, inferiora eius vero menbra asini sunt (191r).

London, B.L., Royal 6.A.XI : Similiter et onocentauros duabus naturis constare Phisiologus asserit, id est: superior pars hominis similis, inferiora vero eius deteriora sunt menbra asini: natura vero eius valde agrestis $(145 \mathrm{v}-146 \mathrm{r})$.

BIs : Onocentaurum duabus naturis constare Phisiologus asserit, id est: superior pars hominis similis, inferioris vero partis menbra sunt nature valde agrestis (ed. MANN : 46).

\section{Pantera}

Ldnr, 4.87, De panthera : Est autem hoc animal admodum mansuetum. Inimicum autem solum habet draconem. Dum comederit satiatumque fuerit diversis cibis, recondit se, ut Phisiologus dicit, in spelunca sua et dormit. Inde post triduum exsurgens sompno rugitum emittit. Cetere vero bestie cum vocem eius audierint, congregantur et sequuntur odoris suavitatem, qui egreditur de ore ipsius, sed capitis sui torvitate terrentur. [...] Solus draco, cum vocem eius audierit, timore contrahitur et fulcit se in cavernis terre.

Y : Panther hanc naturam habet: omnium animalium amicus est, inimicus autem draconi; omnimodo uarius est sicut tunica Ioseph, et speciosus. Etenim dixit Dauid in XLIIII psalmo: Adstitit regina a dextris tuis in uestimento deaurato operta uarietate. Panther quietum animal est, et mitissimum nimis. Si autem manducauerit, et satiatus fuerit, ilico dormit in fouea, et tertio die surgit a somno (sic et saluator noster). Panther autem, si surrexerit de somno tertio die, exclamat uoce magna, et de uoce eius omnis odor bonus aromatum; et qui longe sunt et qui prope, audientes eius uocem, assequuntur bonum odorem uocis eius (ed. CARMODY : 124-125). 
B : Est animal quod dicitur panthera, varium quidem colore, sed speciosum valde, nimis mansuetum. Physiologus dicit de eo quoniam inimicum solum draconem habet. Cum ergo comederit et saciaverit se diversis venationibus, recondit se in speluncam suam, ponit se et dormit. Post triduum exurgit a somno et statim emittit rugitum magnum. Simul autem cum rugitus exit de ore eius, odor suavitatis ita ut superet omnnia aromata. Cum ergo audierint vocem eius omnes bestie, que prope sunt et que longe, congregant se omnes et sequuntur suavitatis odorem qui exit de ore eius. Solus autem draco, cum audierit vocem eius, timore contra[h]itur et fulcit se in terraneis cavernis terre (ed. CARMODY : 40-41).

A : Panthera hanc naturam habet: omnium animatium amicus est, inimicus autem draconi. Omni modo varius sicut tunica Ioseph et spetiosus. Etenim dicit: Astitit regina a dextris tuis in vestitu deaurato operta varietate. Panther quietum animal est et mitissimum. Si autem mandcaverit et sacitus fueri, dormit in sua spelunca, et tercia die surgit a sumno sic et Salvator noster pariter surrexit a sumno tertia die, et quum surrexerit de loco suo et foris exierit vociferat voce magna et de voce eius omnis odor bonus procedit aromatum; qui sunt longe et qui sprope audientes eius vocem adsecuntu bonum odorem (ed. CAHIER-MARTIN, IV : 238-239).

Lyon, B.M., 125 : Est animal quod dicitur panthera, varium colorem habens, sed speciosum est valde et mansuetum nimis. Phisiologus dicit de eo quoniam inimicum est draconi soli. Cum ergo comederit et saciaverit de diversis venationibus, recipit se in speluncam suam, et ponit se et dormit. Post triduum vero exurgit de somno et statim omittit rugitum magnum. Simul enim cum rugitus exit de ore eius, odor tante suavitatis ut super omnnia aromata sit. Cum autem audierint vocem eius omnes bestie, et que prope sunt et que longe, congregant se omnes in unum simul et sequuntur eum per odore suavitatis que exit de ore eius. Solus draco, cum audierit vocem eius, timet contrahitur et infulcit se in subterraneis cavernis terre (193r-193v).

London, B.L., Royal 6.A.XI : Item est animal quod dicitur panthera, varium colore, sed speciosum valde, et mansuetissimum. Phisiologus dicit de eo quoniam inimicum est soli draconi. Cum ergo comederit et saciaverit se de diversis venationibus, recipit se in speluncam suam et ponit se et dormit. Post triduum vero exurgit de somno et emittit magnum rugitum. Simul enim cum rugitu de ore eius exit, odor tante suavitatis ita ut super omnnia aromata sit. Cum ergo audierint vocem eius omnes bestie, que prope sunt et que longe, congregant se simul in unum et sequuntur eum per odorem suavitatis que exit de ore eius. Solus draco, cum audierit vocem eius, timore concutitur et fugit in subterranea terre (141v).

BIs : Est animal quod dicitur panthera, varium quidem colore, set preciosum valde, nimis mansuetum. Phisiologus dicit de eo quoniam inimicum solum draconem habet. Cum ergo comederit et saciaverit se diversis cibis, recondit se in speluncam suam, ponit se et dormit. Post triduum exurgit a sompno et statim emittit rugitum magnum. Cum autem rugitus exierit de ore eius, odor suavitatis exit super omnia aromata. Cum autem audierint vocem eius omnes bestie, que prope sunt et que longe, congregant se omnes et sequuntur suavitatis odorem qui exit de ore eius. Solus autem draco, cum audierit vocem eius, timore contra[h]itur et fulcit se in terraneis cavernis terre (ed. MANN : 56$)$.

\section{Unicornis}

Ldnr, 4.104, De unicorni : occiditurque vel in regali palatio ad spectaculum exhibetur. 
$Y$ : Non potest ei uenator appropiare, propter quod ualde fortissimum est. Quomodo ergo eum uenantur? uirginem castam proiciunt ante eum; exilit in sinum uirginis, et illa calefacit eum, et nutrit illud animal; et tollit in palatium regum (ed. CARMODY : 128).

B : Et nullus omnino venator eum capere potest; sed hoc argumento eum capiunt: puellam virginem ducunt in illum locum ubi moratur et dimittunt eam in silvam solam; at ille vero, ox ut viderit eam, salit in sinum virginis et complectitur eam, et sic comprehenditur, et exhibetur in palatio regis (ed. CARMODY : 31 ).

A : Et nullus omnino venatorem capere potest; hoc argumento capitur: puellam virginem ducit in loco illo ubi ipse moratur et dimittit eam in silva solam; rinoceros vero ut viderit illam, insilit in sinum virginis et anplectitur eam, et sic capitur ${ }^{80}$, et exhibetur in palatio regis ${ }^{81}$ (ed. CAHIERMARTIN, II : 221-226).

Lyon, B.M., 125 : Et quia nullus venator omnino eum capere potest; hoc argumento capiunt: puellam virginem ducunt in illum locum ubi moratur et domittunt eam in silva solam; ille vero, ut viderit eam, salit in sinum virginis et complectitur eam, et sic comprehenditur, et exhibetur in palatio regum (192r).

London, B.L., Royal 6.A.XI : Nullus venator eum omnino capere potest; sed tamen hoc ingenio capiunt eum: puellam virginem ducunt illum ubi moratur et dimittuntur in silva solam; ille vero, ut viderit eam, mox salit in sinum eius et complectitur eam, et sic comprehenditur, et exhibetur in palatio regum (146r).

BIs : Et nullus omnino venator eum capere potest; sed hoc argumento eum capiunt: puellam virginem ducunt in illum locum ubi moratur et dimittunt eam in silvam solam; at ille, visa virgine, complectitur eam et dormiens in gremio eius comprehenditur ab exploratoribus eius et exibetur in palatio regis (ed. MANN : 49).

\section{Caladrius}

Ldnr, 5.24, De caladrio : Huius pars interior femoris caliginem aufert ab oculis. [...] Has vero aves reges antiquitus in atriis recludebant regalibus.

$Y$ : Et interiora eius apudeumata curant his quorum oculi caligant: in atriis autem regum inuenitur (ed. CARMODY : 105).

B : Cuius interius fimus curat caliginem oculorum. Istud in atriis regum invenitur (ed. CARMODY : 15).

A : Cuius interius fimus curat caliginem oculorum. Istud in atriis regum invenitur (ed. CAHIERMARTIN, II : 130-134).

Lyon, B.M., 125 : Cuius interius fimus curat caliginem oculorum. Istud in atriis regum invenitur (190r).

London, B.L., Royal 6.A.XI : Cuius interius fimus caliginem oculorum curat. Istud invenitur in atriis regum $(144 \mathrm{v})$.

BIs : Cuius interius femur curat caliginem oculorum. Istud in atriis regum invenitur (ed. MANN : 49). 


\section{Columba}

Ldnr, 5.36, De colomba : Est arbor quedam Orientis, sicut dicit Ysidorus, que Grece 'peredixion' dicitur, Latine vero 'circa dextram'. Fructus huius arboris dulcis est, quo columbe mirifice delectantur. Umbra vero et ramis eius proteguntur. Est autem in ipsis partibus quoddam drachonum genus, quod ipsis columbis insidiatur. Ipse autem draco naturaliter ipsam arborem perhorrescit adeo, ut umbra illius formidet attingi. Sedentibus ergo columbis in arbore procul insidiatur draco et respicit, si ulla earum arborem deserat et sibi preda fiat. Si autem fuerit umbra parte sinistra, dextram dracho petit, si dextra sinistram. Drachones intellige demones, columbas animas fideles, peredixion crucem Christi, cuius circa dextram mater eius, umbra arboris signum crucis.

$Y$ : Est arbor que dicitur peridexion, inuenitur in India. Fructus autem arboris illius dulcis est totus ualde, et suauis. Columbe autem delectantur in fructu arboris illius: habitant autem in ea pascentes fructu eius. Inimicus est autem dracho columbis, timet autem arborem illam et umbram eius, in qua columbe demorantur: et non potest draco adpropiare columbis neque umbre eius. Si enim umbra arboris uenerit ad occidentem, fugit draco ad orientem; si iterum uenerit umbra eius ad orientem, fugit ad occidentem. Si autem fiet ut columba inueniatur foris arborem aut umbram eius, et inuenerit eam draco, occidit eam (ed. CARMODY : 116-117).

B : Est arbor que dicitur Indie, que dicitur Grece peritexion, latine vero circa destrum dicitur. Cuius fructum dulcis est nimis et ualde suauis. Columbe igitur satis delectantur in istius arboris gratiam: quam et de fructus eius reficiuntur et sub umbra eius requiescente ramis eius proteguntur est autem draco crudelis nimis inimicus colubarum et quantum columbe dracone timent et fugient eum, tanto plus draco illam arborem excircat et pertimescit ita ut nec umbre illius adpropinquare ausus sit sed dum insidiatur columbis ille draco ita ut capiat ex eis de longe considerat ad illam arbore et si fuerit umbra arboris a parte dextra, ille parte sinistra se facit, si autem fuerit umbra eius a parte sinistra ille fugiens eam ad dextram se facit (Montecassino, Archivio dell'Abbazia, $323: 102-103^{82}$ ).

A : Hec arbor invenitur in India, fructus autem arboris huius dulcis est totus et valde suavis; columbe autem delectantur in fructu arboris illius, habitant autem in ea fascentes $<$ sic $>$ fructus eius. Inimicus est autem draco columbis; timet autem arborem illam et umbram eius ubi columbe demorantur, et non potes draco appropiare arbori neque umbre eius. Si enim umbra erboris venerit ad Occidentem, fugit draco ad Orientem, si iterum venerit umbra eius ad orientem, fugit ad Occidentem. Si autem fiat ut columba inveniatur foris arborem aut umbre sic eius, et inveniat eam draco, occidit eam (ed. CAHIER-MARTIN, II : 130-284-285).

Lyon, B.M., 125 : Hec invenitur in India, fructus enim arboris illius dulcis est totus et valde suavissimus; columbe vero delectantur in umbra arboris illius habitare et habitant in ea de fructibus enim eius bibunt. Inimicus est autem draco columbarum, sed timet autem arborem illam et umbram eius in quam columbe demorantur, et non potes adpropiare columbis neque umbre arboris. Si enim umbra eius venerit ad Occidentem, draco fugit ad Orientem, si iterum venerit umbra eius ad Orientem, fugit ad Occidentem. Et si evenerit ut columba inveniatur extra arborem aut umbram eius, occidit eam draco (194v).

London, B.L., Royal 6.A.XI : Hec arbor invenitur in India, fructus eius dulcis est totus et valde suavis; columbe vero delectantur in umbra eius et habitant in ea de fructu eius viventes. Draco etiam inimicus columbis est, et timet autem arborem illam et umbram eius in quam columbe demorantur, et non potes appropinquare draco columbis neque umbre arboris. Si enim umbra eius venit ad Orientem, draco fugit ad Occidentem, si autem ad Occidentem, fugit ad 
Orientem . Et si evenerit ut columba inveniatur extra arborem aut umbram eius, occidit eam draco (143r).

BIs : Arbor quedam est in partibus Indie, que grece peredixion, latine vero circa dexteram cuius fructus dulcis est nimis et valde suavis. Columbe autem satis delectantur in istius arboris gratia, quoniam de fructu eius reficiuntur et sub umbra eius requiescunt et ramis eius proteguntur. Est autem draco crudelis inimicus columbarum; et quantum columbe timent draconem et fugiunt ab eo, tantum ille draco evitat et pertimescit illam arborem, ita ut nec umbre illius appropinquare ausus sit. Set dum insidiatur columbis ille draco, ut rapiat aliquam earum, de longe considerat illam arborem. Si umbra illius arboris fuerit in parte dextera, se facit ille in parte sinistra. Si autem fuerit umbra illius in parte sinistra, ille fugiens in parte dextera se facit. Columbe autem scientes inimicum suum draconem timere illam arborem et umbram illius, et omnino nec leviter appropiare illi posse, ideo ad illam arborem confugiunt et ibi se commendant, ut salve esse possint ab insidiis adversarii earum. Dum ergo in illa arbore fuerint et in ipsa se continuerint, nullo modo potest eas capere draco. Si autem invenerit aliquam ex eis vel leviter segregatam ab arbore, vel extra umbram illius, statim eam rapit et devorat. Et hec quidem refert Phisiologus de columbis (ed. MANN : 66).

\section{Phoenix}

Ldnr, 5.45, De phoenice : Ysidorus dicit: Helyopolim, civitatem Egypti, mense Adar, id est Aprilis, ingressam fuisse avem fenicem oneratis utrisque alis diversis aromatibus, et abscondisse struem sarmentorum, qui coniectus fuerat in sacrificium a sacerdote Domini, seque super struem inter aromata, que in alis suis detulerat, combussisse. Prima autem die post diem combustionis veniens sacerdos invenit combusta ligna, que posuerat super dextram aram, et, scrutans cynerem, vermiculum invenit modicum suavissimo odore fraglantem. Secunda autem die vermiculus in avem formatam inventus est. Tertio autem die in statu suo integra atque perfectissima sacerdoti valefaciens evolavit.

$Y$ : Est enim uolatile genus in Indie partibus quod dicitur phenix; que auis per quingentos annos intrat in ligna Libani, et implet duas alas suas aromata. Et significat sacerdoti Heliopoleos (ciuitas hec que Heliopolis nomen habet) in mense nouorum, hoc est Adar, quod grece dicitur Farmuti uel Phamenoth. Sacerdos autem cum significatum ei fuerit, intrat et implet aram lignis sarmenteis; et intrans illa auis in Heliopolim onerata aromatibus, ascendit super aram, et sibi ipsa ignem incendit, et seipsam conburit. In crastinum enim sacerdos scrutatur aram, et inueniet uermem in cineribus. Secundo autem die inuenit auiculam pusillam. Tertio die inueniet aquilam magnam: et euolans, salutat sacerdotem, et uadit in antiquum locum suum (ed. CARMODY : 108-109).

B : Et quibusdam indiciis significatur hoc sacerdoti civitatis Eliopolis, id est mense nono, nisan, aut adar, id est sarmat aut famenoht, quod est aut marcio aut aprili mense. Cum autem hoc significatum fuerit sacerdoti, ingreditur et implet aram de lignis sarmentorum. Cum advenerit volatile, intrat in civitatem Heliopolim, repletum omnibus aromatibus in utrisque alis suis; et statim videns factam struem sarmentorum super aram, ascendit, et circumvolvens se de aromatibus, ignem ipse sibi incendit et seipsum exurit. Alia autem die veniens sacerdos videns exusta ligna, que composuerat super aram, scrutans, invenit ibi vermiculum modicum suavissimo odore fragrantem. Secundo vero die invenit iam aviculam figuratam. Rursum tercia die veniens sacerdos, invenit eam iam in statu suo integram atque perfectam avem fenicem. Et vale dicens sacerdoti, evolat et pergit ad locum suum pristinum (ed. CARMODY : 20). 
A : Et quibusdam indiciis significatur hoc sacerdoti civitatis Eliopolis ${ }^{83}$, id est mense nono, nisan, nautdar, id est mense frarmuth, quod est marcio aut aprili mense. Quum autem hoc significatum fuerit sacerdoti, ingreditur et implet aram de lignis sarmentorum. Quum autem advenerit volatile illud, intrat in civitatem Eliopoli, repletas alas suas aromatibus et statim videns factum struem sarmentorum super aram, ascendit, et circumvolvens se de aromatibus, ignem sibi incendit et se ipsam exurit. Alia autem die veniens sacerdos et videns exusta ligna, que composuerat super aram, et scrutans diligenter, invenit vermiculum modicum suavissimi odoris fraglantem. Secondo vero die veniens, invenit iam aviculam figuratam. Perfecta autem pheonica valefaciens sacerdoti tercia die veniens sacerdos, invenit eam stato suo integram atque perfectam seneam valefacientem sacerdoti $i^{84}$, evolat et pergit ad pristinum locum suum (ed. CAHIER-MARTIN, II : 183-186).

Lyon, B.M., 125 : Et quibusdam inde significatur hoc sacerdoti Eliopoletis civitatis, id est mense nisan, aut adar, hoc est farmoth aut fanmoth, quod est marcio mense aut aprili mense. Cum autem significatum fuerit sacerdoti, ingreditur et implet aram de lignis sarmentorum. Cum enim venerit volatile illud, intrat in civitatem Eliopoletis, repletas omnibus aromatibus alis suis et statim factam statuam sarmentorum super ascendends et circumvolens se de aromatibus, ignem etiam incedit et seipsum exurit. Alia autem die veniens sacerdos videt exusta ligna, que composuerat super aram, scrutans vero invenit ibi vermiculum modicum suavissimo odore fraglantem. Secondo vero die veniens, invenit ea iam aviculam figuratam. Rursum tercia die veniens sacerdos, invenit eam tatu suo integram atque perfectam ave fenicem. Et vale dicens sacerdoti, evolat et pergit ad pristinum locum suum (190v).

London, B.L., Royal 6.A.XI : Dicit Phisiologus quia expletis quingentis vite sue annis intrat in lignorum Libani [-]gerie[-] ${ }^{85}$ et implet alas utrasque diversis diversis aromatibus et statim factam struem lignorum ascendens <sic> et circumvolans se cum aromatibus ignem succendit es se ipsam exurit Rursus tertia invenitur statu suo integra atque perfecta et evolat ad pristinum locum suum (145r).

BIs : Et quibusdam indiciis significatur sacerdoti civitatis Eliopolis mense novo, id est nisan, aut adar, id est sarmat, aut famenoht, quod est aut marcio, aut aprili mense. Cum autem hoc significatum fuerit sacerdoti, ingreditur et implet aram de lignis sarmentorum. Cum advenerit volatile, intrat in civitatem Eliopolim, impletum omnibus aromatibus in utrisque alis suis; et statim videns factam struem sarmentorum super aram, ascendit, et circumvolvens se de aromatibus, ignem ipse sibi incendit et seipsum urit. Alia autem die veniens sacerdos exustaque ligna, que composuit super aram, scrutans, invenit ibi vermiculum modicum suavissimo odore fragrantem. Secundo vero die invenit iam aviculam figuratam. Rursum tercia die veniens sacerdos, invenit eam iam in statu suo integram atque factam avem fenicem. Et vale dicens sacerdoti, evolat et pergit ad locum suum pristinum (ed. MANN : 43).

\section{Fulica}

Ldnr, 5.46, De fulica : Hoc volatile intelligibile et prudentissimum super omnia volatilia dicitur. Cadaveribus non vescitur. In nullis diversis locis commoratur vel oberrat, sed in solo loco se quietam tenet usque in finem vite sue. Escam suam circa se colligit.

$Y$ [De herodion id est fulica] : Est autem hoc animal satis prudens pre omnibus uolatilibus; non multos cubiles querens, sed ubi moratur, ibi et pascit, et reuertitur ibi et dormit; neque morticina manducat, neque uolat in multis locis: cubile eius et esca in uno loco sunt (ed.

CARMODY : 122-123). 
B : Est volatile quod dicitur fulica, satis intelligibile, et prudentissimum super omnia volatilia. Cadaveribus non vescitur, non aliunde alibi pervolans atque oberrans, sed in uno loco commoratur et permanet usque in finem, et ibi escam suam habet et ibi requiescit (ed. CARMODY : 39).

A : Est volatile qui vocatur herodius, David dicente: Fulicae domus dux est eorum. Est autem volatile prudentissimum prae omnibus volatilibus, non multa copia [sic] quaerens, sed moratur ubi et dormit neque morticinum manducat, nec volât in multis locis (ed. CAHIER-MARTIN, III : 209).

Lyon, B.M., 125 [De folice] : Est volatile quod dicitur folice, satis intelligibile, et prudentissimum animal super omnia volatilia. Non cadaveribus vescitur, nec est aliunde alibi pervolans atque oberrans, sed in uno loco commoratur et permanet usque in finem, et ubi escam suam non habet, ibi requiescit (193r).

London, B.L., Royal 6.A.XI [De volatile que dicitur folica] : Item volatile quod dicitur folix, satis intelligibile, et prudentissimum super omnia volatilia. Non cadaveribus vescitur, nec aliunde alibi pervolat atque oberrat, sed in uno loco commoratur et permanet usque in finem, et ibi escam suam habet et ibi requiescit (141v).

BIs : Est volatile quod dicitur fulica, satis intelligibile, et prudentissimum super omnia volatilia. Cadaveribus non vescitur, non de aliunde alibi pervolans atque aberrans, sed in uno loco commoratur et permanet usque ad finem, et ibi escam suam habet et requiescit (ed. MANN : 55).

\section{Ibex}

Ldnr, 5.63, De ybicibus avibus : Circa littora maris vel fluminis vel stagnorum hec avis nocte dieque ambulat querens aut mortuos pisciculos aut aliquod cadaver, quod ab aquis iam putridum vel marcidum eiectum fuerit foras. Aquam tamen nunquam ingreditur, sed tantum eiectis cadaveribus delectatur.

$Y$ : Est animal quod dicitur hibicis; inmundum quidem est, secundum legem, pre omnibus uolatilibus. Natare nescit, sed secundum litorem fluminum uel stagnorum depascit: non potest natare in altitudinem, sed ubi immundi pisciculi demorantur; inuenitur que foris ab altissimis locis (ed. CARMODY : 115-116).

B : Est volatile quod dicitur ibis. Hoc secundum legem inmundum est pre omnibus volatilibus, quoniam morticinis cadaveribus semper vescitur et iuxta littora maris, vel fluvium, vel stagnorum, die noctuque ambulat, querens aut mortuos pisciculos aut aliquod cadaver, quod ab aqua iam putridum vel marcidum eiectum fuerit foras. Nam in aquam ingredi timet, quia natare nescit, nec dat operam ut discat, dum mortuis cadaveribus delectatur (ed. CARMODY : 27).

\section{$A:[$ manca $]$}

Lyon, B.M., 125 : Est volatile quod dicitur hibis. Immundum est pre omnibus volatilibus, quoniam morticinis cadaveribus semper vescitur et secus habetur <sic > maris, vel fluminnum, vel stagnorum, die noctuque ambulat, querens aut mortuos pisciculos aut aliquod cadaver, quod ab aqua iam putridum ac malidum <sic > eiectum fuerit foras. Nam ingredi in aquam timet, quia natare nescit, nec dat operam ut discat, ideo mortuis cadaveribus delectatur (191v).

London, B.L., Royal 6.A.XI : [manca] 
BIs : Est volatile quod dicitur ibex. Hoc secundum legem inmundum est pre omnibus volatilibus, quoniam morticinis cadaveribus semper vescitur et iuxta littora maris, vel fluvium, vel stagnorum, die noctuque ambulat, querens aut mortuos pisciculos aut aliquod cadaver, quod ab aqua iam putridum iam marcidum eiectum fuerit foras. Nam in aquam ingredi timet, quia natare nescit, nec dat operam ut discat, dum mortuis cadaveribus delectatur (ed. MANN : 47).

\section{Structio}

Ldnr, 5.110, De strutione : Structio avis est, ut dicit Ysidorus, que Grece assida vocatur; dicitur et camelon, eo quod pedes habet quasi camelus. Hec avis cum venerit tempus, ut ova pariat, elevat oculos suos ad celum ut videat si stella illa Virgilia ascenderit. Non enim ova sua ponit in terra, nisi stella exorta. Et hec ratio: tempore enim estatis quando messes florent circa mensem Iulium oritur stella Virgilia in celo, et tunc quidem assida, fodit in terra et ibi deponit ova sua et ea cooperit sabulo. Quibus coopertis descendit de loco, ovaque sua mox deposita obliviscitur nec ultra ad ea revertitur. Est enim obliviosa naturaliter. Et ideo calido tempore generat ova sua et in terra sabulo cooperit, ut, quod illa factura erat sedens et fovens, hoc illi tranquillitas temporis et aeris temperies prestare videatur. Unde de ipsa ave Ieremias propheta dicit: assida in celo cognovit tempus suum. Igitur ovis calefactis harena a Sole irradiata, pulli educuntur ab eis.

$Y:[$ manca $]$

B : Item est animal quod dicitur assida, quod grece struthiocamelon, latini struthionem dicunt. De isto animali Hieremias propheta dicit: et asida in celo cognovit tempus suum. Phisiologus dicit hoc quasi volturium esse. Habet quidem pennas, set non volat sicut cetere aves; pedes vero habet similes camelo, et ideo grece structucamelon dicitur. Hoc ergo animal, cum venerit tempus suum ut ova pariat, elevat oculos suos in celum et videt si stella illa que dicitur Virgilia ascendit. Non enim ponit ova sua in terra, nisi quando stella illa oritur in celo. De qua stella dicit Iob: Qui facit Virgiliam et septentrionalem et dextrum et promtuaria austri. Tempore enim suo oritur Virgilia stella in celo, id est quando messes florent et estas est, circa mensem iunium. Tunc assida, cum viderit Virgiliam ascendisse in celum, fodit in terra et ibi ponit ova sua et cooperit ea de sabulone in heremo; cum autem ascenderit de illo loco, statim obliviscitur, et non redit ad ova sua. Est enim hoc animal naturaliter obliviosum; et ideo tempore estatis generat ova et obruit illa de arena, ut, quod illa factura esset sedens super ova sua et ex fetu suo, eduxeret pullos suos, hoc ei temporis tranquillitas et aeris temperies prestare videatur, ut estate calefacta arena excoquat ova et excludat ${ }^{86}$ pullos (ed. CARMODY : 48).

A : Item est qui dicitur isida, quod grece dicitur structo camelon, latine strutio. De isto animali Hieremias propheta dicit: et isida in celo cognovit tempus suum. Phisiologus dicit hoc quasi volatle esse. Habet quidem pennas, sed non volat sicut cetere aves; pedes vero habet similes camelo dicitur ${ }^{87}$. Hoc ergo animal, quum venerit illi tempus suum ut ova pariat, elevat oculos suos in celum et viderit stellam que dicitur Virgiliaca iam ascendisse. Non enim ponit ova sua in terra, antequam illa oriatur in celo. De qua stella dicit Iob: Qui facit Virgilia et dextrum ${ }^{88}$ et septentrionalem et promtuaria austri. Tempore enim suo oritur Virgilia stella in celo, id est quando messes florent et estas est, circa mensem iunio ${ }^{89}$. Tunc isida, quum viderit Virgiliam ascendisse in celum, fodit in terra et ibi ponit ova sua et cooperit ea de sablone in heremo; quum autem abscesserit de loco illo, statim obliviscitur, et non redit ad ova sua. Est enim animal obliviosum; et ideo tempore estatis generat ova et obruit illa de arena, ut, quod illa factura erat sedens super ova sua ut fetu, educeret pullos suos ${ }^{90}$, hoc ei temporis tranquillitas et aeris 
temperies prestare videatur, ut statim calefacta arena exquoquat ova et excludat pullos suos (ed. CAHIER-MARTIN, III : 258-259).

Lyon, B.M., 125 : [manca]

London, B.L., Royal 6.A.XI : [manca]

BIs : Item est animal quod dicitur assida, quod grece strictecamelon, latine struccio dicitur. Phisiologus dicit hoc quasi volturium esse. Habet quidem pennas, set non volat sicut cetere aves; pedes autem habet similes camelo, et ideo grece structucamelon dicitur. Hoc ergo animal, cum venerit tempus illud ut ova pariat, elevat oculos suos in celum et videt si stella illa Virgilia ascendit. Non enim ponit ova sua in terra, nisi quando illa stella oritur in celo. De qua stella dicit Iob: Qui facit Virgiliam et septentrionalem et dextrum et promtuaria austri. Tempore enim suo oritur Virgilia in celo, id est quando messes florent et estas est, circa mensem iunium. Tunc assida, cum viderit Virgiliam ascendisse in celum, fodit in terram et ibi ponit ova sua et cooperit ea de sabulo in heremo; cum autem ascenderit de illo loco, statim obliviscitur, et non redit ad ova sua. Est enim animal hoc naturaliter obliviosum; et ideo tempore isto generat ova sua et operit illa de harena, ut, quod illa factura esset sedens super ova sua et ex fetu suo, educeret pullos suos, hoc ei tranquillitas temporis et aeris temperies prestare videatur, ut estate calefacta arena excoquat ova sua et educat pullos (ed. MANN : 61).

\section{Huppupa}

Ldnr, 5.117, De huppupa : Senescentes parentes plumas in nido inter pullos iam adultos exuunt, et iterum a pullis pascuntur, donec vires et plumas recuperent. Dicit Physiologus quod alia inest eis pietas erga parentes suos. Cum enim parentes eorum senio visum perdiderint, pulli naturaliter notam herbam colligunt, et inde liniunt cecatos parentum oculos, ut herbe antidoto oculorum recuperent claritatem.

$Y$ : Et quomodo sunt patricide aut matricide? Est auis que dicitur epopus: si uiderit suos parentes senuisse, et eorum oculos caliginasse, filii uellunt pinnas parentum, et elingunt oculos eorum, et calefaciunt parentes suos sub alis suis, et nutriunt parentes suos, uicem eis reddentes, et nutriunt sicut pullos suos, et noui fiunt parentes ipsorum (ed. CARMODY : 109).

B : Phisiologus dicit: est avis que dicitur huppupa. Horum filii, cum viderint parentes suos senuisse, et neque volare posse, neque videre pre caligine oculorum, tunc filii eorum evellunt vetustissimas pennas parentum suorum et diligunt oculos parentum suorum et fovent eos sub alas suas, donec recrescant penne eorum et reilluminentur oculi eorum, ita ut totum corpore renovari possint, et sicut antea et videre et volare (ed. CARMODY : 48).

A : Est auis que dicitur epopus: si uiderit senuisse, et caliginasse oculos eorum, euellunt plumas parentum, et oculos eorum lingunt, et calefaciunt parentes suos et noui fiunt parentes eorum; et dicunt parentibus suis: sicut laborastis nutrientes nos, similiter nobis facimus (ed. CAHIERMARTIN, III : 258-259).

Lyon, B.M., 125 : [manca]

London, B.L., Royal 6.A.XI : Est auis que dicitur upupa. Phisiologus dicit quod harum filii, cum viderint parentes suos senuisse, nec volare posse, nec videre pre caligine oculorum, vetustissimas pennas illorum suis linguis et oculorum lingunt et illuminatur oculi eorum ita ut toto corpore renovari possint sicut antea. Sic ergo irrationabilia volatilia parentibus suis vincere inducere satagunt $<$ sic $>(145 \mathrm{v})$. 
BIs : Phisiologus dicit: est avis que dicitur huppupa. Horum filii, cum viderint parentes suos senuisse, ut neque volare possint, neque videre pre caligine oculorum, tunc filii eorum evellunt vetustisimas pennas parentum suorum et linniunt oculos parentum suorum et fovent eos sub alis suis, donec recrescant penne eorum et reilluminentur oculi eorum, ita ut toto corpore suo renovari possint, et sicut antea videre et volare (ed. MANN : 43).

\section{Serra}

Ldnr, 6.43, De serra maiori : Serra marina belua est, ut Ysidorus dicit, corpore ingens pennasque habens latissimas et alas immanes. Hec bestia cum viderit navem velificantem in pelago, elevat alas suas super aquas et in contrarium navis velificare contendit. Cumque stadiis triginta vel etiam quadraginta aliquando hec conata fuerit nec prevaluerit, tandem laborem non sustinens deficit, deponensque pennas suas ad se retrahit. Fluctus vero lassam reportat ad locum pristinum in profundum maris.

$Y$ : Est inquid animal in mari quod dicitur serra, alas habens longas. Et si uiderit naues nauigantes, imitatur eas, et exaltat alas suas, et contendit cum nauibus que nauigant; et cum fecerit stadia triginta aut quadraginta, aut eo amplius, laborans in se, alas suas colligit, et fluctus eam referunt in ueterem suum locum, ubi prius erat (ed. CARMODY : 105).

B : Est belua in mari que dicitur serra, pennas habens immanes. Hec cum viderit in pelago navem velificantem, elevat pennas suas et contendit velificare cum nave. Ubi vero currerit contra navem stadiis triginta vel quadraginta, laborem non sustinens, deficit, et, deponens pennas, ad se attrahit eas; unde vero maris iam lassum reportant eam ad pristinum locum suum in profundum (ed. CARMODY : 14).

A : Est belua in mare que dicitur serra, pennas habens immanes. Hec quum viderit navem in pelago velificantem, elevat pennas suas super aquas et contendit velificare contra nave. Ubi currerit contendendum contra ${ }^{91}$ navem stadiis triginta vel quadraginta, laborem non sustinens, deficit, et, deponens pennas suas, ad se adtrahit eas; unde vero iam lassam reportant eam ad pristinum locum suum in profundum mare (ed. CAHIER-MARTIN, II : 122).

Lyon, B.M., 125 : Hec cum que contra navem certat viderit in pelago navem velificantem, elevat pennas suas super aquas et contendit velificare cum nave. Ubi vero currerit contendendo contra navem stadiis triginta vel quadraginta, laborem non sustinens, deficit, et, deponens pennas, ad se adtrahit eas; unde vero maris iam lassam reportant eam ad pristinum locum suum in profundum maris (189v).

London, B.L., Royal 6.A.XI : [manca]

BIs : Est belua in mari que dicitur serra, pennas habens immanes. Hec cum viderit in mare navem velificantem, elevat pennas suas et contendit velificare cum nave. Ubi autem contendit currere contra navem stadiis .xxta. vel .xlta., laborem non sustinens, deficit, et, deponens pennas, ad se trait eas; unde vero maris iam lassum reportant eum ad pristinum locum suum in profundum (ed. MANN : 39).

\section{Siren}

Ldnr, 6.45, De syrenis : Syrene animalia vocifera sunt, ut dicit Phisiologus, que a capite usque ad umbilicum figuram mulieris habent procere magnitudinis, facie horrenda, crinibus capitis longissimis atque scalentibus. [...] Quoddam musicum ac dulcissimum melos habent in voce, qua 
navigantes delectati et attracti resolvuntur in sompnum, sompnoque sopiti syrenarum unguibus dilacerantur.

$Y$ : Unius cuiusque naturam Phisiologus disseruit, dicens de sirenis, quoniam animalia mortifera sunt in mari, clamitantia uocibus aliis; etenim dimidiam partem usque ad umbilicum hominis habent figuram, dimidio autem uolatilis (ed. CARMODY : 113-114).

B : Unius cuiusque natura Phisiologus disseruit: Sirene, inquit, animalia sunt mortifera que ad capite usque ad umbilicum figuram hominis habent, extrema vero pars usque ad pedes volatilis habent figuram; et musicum quoddam ac dulci sonum melodie carmen canunt ita ut per suavitatem vocis auditus hominum a longe navigantium mulceant et ad se trahant, ac nimia suavitate modulationis prolixe aures ac sensus eorum delinientes in sompnum vertunt. Tunc deinde, cum viderint eos gravissimo sompno sopitos, invadunt eos et dilaniant carnes eorum, ac sic persuasionis vocis ignaros et insipientes homines decipiunt et mortificant sibi. Sic igitur et illi decipiuntur qui deliciis huius seculi et pompis et theatralibus voluptatibus delectantur, tragediis ac diversis musicis melodiis dissoluti et velut gravati sompno sopiti, efficiuntur adversariorum preda (ed. CARMODY : 25).

A : Unius cuiusque naturam Physiologus disseruit: Sirene, inquit, animalia sunt mortifera que ad capite usque ad umbilicum figuram hominis habent, extremas vero partes usque ad pedes volatiles habent et figuram; musicam quoddam ac dulcissimum melodie carmen ita ut per suavitatem vocis auditus hominum a longe vigilantium mulceant et ad se trahant, ac nimia suavitatis modulationis perlectant aures ac sensus eorum delectantes in somno vertant. Tunc demum, quum viderint eos in gravi somno subito, invadunt et dilaniant carnes eorum, ac sic persuasionis vocis ignaros et incautos homines decipiunt et mortificat. Sic igitur et illi decipiuntur qui in deliciis et pompis et teatralibus ac voluptatibus delectantur, id est comediis et tragediis ac diversis musicis melodiis dissoluti et velut in sompno grave totum mentis vigorem amittunt, et subito effitiuntur adversariorum virtutum avidissime prede (ed. CAHIER-MARTIN, II : 122).

Lyon, B.M., 125 : Unius cuiusque naturam Fisiologus disseruit: Sirene, inquit, animalia sunt mortifera que ad capite usque ad umbilicum figuram hominis habent, in extremas vero partes usque ad pedes volatiles habent figuram et musicam quoddam dulcissimum melodie carmen canunt ut per suavitatem vocis auditus hominum a longe vigilantium mulceant et ad se trahant, ac nimia suavitatis modulationis perlectant aures ac sensus eorum delectantes in somnum vertunt. Tunc deinde, cum viderint eos gravissimo somno sopitos, invadunt et dilaniant carnes eorum, ac sic persuasionis vocis ignaros et incautos homines decipiunt et mortificant. Sic igitur decipiuntur et illi qui deliciis et pompis dyabolicis et theatralibus voluptatibus delectantur, id est comediis et tragediis ac diversis musicis melodiis dissoluti et velut somno gravi toto mentis vigore sopiti efficiuntur adversaria virtutum avidissima preda (191r).

London, B.L., Royal 6.A.XI : Unius cuiusque naturam Phisiologus disseruit: Sirenes, inquit, animalia mortifera sunt que a capite usque ad umbilicum figuram hominis habent, extremam parte, usque ad pedes volatilem habent et musicam ac dulcissimum carmen cantatur ita ut per suavitatem vocis auditus hominum longe navigantium mulceant, ac nimia suavitatis modulatione aures ac sensus in sompnum convertant. Deinde, cum viderint eos gravissimo sompno sopitos, invadunt et dilaniant carnem eorum, ac sic ignaros et incautos decipiunt et mortificant. Sic ergo decipiuntur et omnes qui deliciis et pompis diabolicis et teatralibus voluptatibus delectantur, id est tragediis comdans ac diversis musicis melodiis dissoluti et velut sompno gravi sopiti efficiuntur adversariorum preda (145v). 
BIs : Sirene, inquid, animalia sunt mortifera. Phisiologus describit: usque ad umbilicum figuram hominis habent, extrema vero pars usque ad pedes volatilis habet figuram; et musicum quoddam ac dulcisonum melodie cantum canunt ita ut per suavitatem vocis auditus hominum a longe navigantium mulceant et ad se trahant, ac nimia suavitate modulationis prolixe aures ac sensus eorum delinientes in sompnum vertant. Tunc deinde, cum viderint eos gravissimo sompno sopitos, invadunt eos et dilaniant carnes eorum, ac sic persuavis voces soni ignaros et insipientes homines decipiunt et mortificant sibi. Sic et illi qui deliciis huius seculi et pompis et theatralibus voluptatibus delectantur, tragediis ac comediis dissoluti velut gravi sompno sopiti, adversariorum preda efficiuntur (ed. MANN : 46).

\section{Cetus}

Ldnr, 7.19, De cethe : Ysidorus: Hec harenas aliquando sustollunt dorsis, in quibus urgente tempestate cum naute inciderint terram se invenisse gaudentes, ut pausent a fluctibus, anchoras iactant velisque depositis, cum quiescere sperant, in firmitate falsa ignes accendunt; quos, ut belua senserit, improvise ac subito commota demergitur secumque tam naves quam homines trahit in profundum.

$Y$ : Phisiologus autem dixit de ceto quoddam, quod est in mari, nomine aspidoceleon uocatur, magnum nimis, simile insule, et plus quam harena grauis, figuram habens diabuli. Ignorantes autem naute, alligant ad eum naues sicut ad insulam, et anchoras et palos nauis configunt in eo; et accendunt super eum ignem ad coquendum sibi aliquid; si autem excaluerit cetus, urinat, descendens in profundum, et demergit omnes naues (ed. CARMODY : 125).

B [Aspichelone] : Hec in medio pelago elevat dorsum suum super undas maris sursum, ita ut navigantibus nautis non aliud credatur esse quam insula, precipue cum viderint totum locum illum sicut in omnibus litoribus maris sabulonibus esse repletum. Putantes autem insulam esse, applicant navem suam iuxta eam et descendentes, figunt palos et alligant naves. Deinde ut coquant sibi cibos post laborem, faciunt ibi focos super arenam quasi super terram. Illa vero belva, cum senserit ardorem ignis, subito mergit se in aquam et navem secum trahit in profundum maris (ed. CARMODY : 44).

\section{$A:[$ manca $]$}

Lyon, B.M., 125 [Aspidotes] : Hec in medio maris elevat dorsum suum super undas maris, ita ut navigantibus nautis non aliud credatur esse quam insula, precipue cum viderint totum illum sicut in omni littore maris sabulonibus esse repletum. Putantes ergo insulam esse, applicantes navem suam iuxta eam et descendentes, figunt palos et alligant navem. Deinde in quoquant sibi cibum et post laborem, faciunt sibi focum super arenam quasi super terram. Illa vero belva, cum senserit ardorem ignis, subito mergit se sub aquam et navem secum trahit in profundum maris (193v-194r).

London, B.L., Royal 6.A.XI [Testudo] : Hec in medio pelagi elevat dorsum suum super undas maris, ut a navigantibus non aliud credatur esse quam insula, precipua cum enim viderint totum locum illum sicut in littore maris sabulo esse plenum. Putantes insulam esse, aplicantes navim suam iuxta eam et descendentes, palos figunt et alligant navem. Deinde ibi cocunt sibi cibum et post laborem, et faciunt focum super arenam quasi super terram. Illa vero belva, cum sentit ardorem ignis, subito mergit se sub aquam et navem secum trahit in profundum maris $(142 v)$. 
BIs [Cetus] : Hec in medio pelagi elevat dorsum suum per undas maris sursum, ita ut navigantibus nautis non aliut credatur esse quam insula, precipue cum viderint totum illum locum sicut in omnibus litoribus maris sabulo esse repletum. Putantes autem insulam esse, applicantes navem suam iuxta eam et descendentes, figunt palos et alligant naves. Deinde ut coquant sibi cibos post laborem, faciunt ibi focos super arenam quasi super terram. Illa vero, ut senserit ardorem ignis, subito mergit se in aqua et navem secum trahit in profundum maris (ed. MANN : 58-59).

\section{Idros}

Ldnr, 8.21, De ydro : Idros, ut dicit Ysidorus, in Nilo flumine serpens est. Hic cum viderit cocodrillum aperto ore super ripas Nili fluminis dormientem, volvit se lutoso limo, quo facilius possit illabi faucibus cocodrilli. Desoporatus igitur cocodrillus illapsum transglutit. Mox dilaniatis visceribus eius vivus egreditur.

$Y$ : Est animal quod dicitur niluus, hoc est in flumine, figuram habens canis. Inimicus autem est corcodrilli; si autem uiderit corcodrillum dormientem, et apertum os eius, uadit niluus et unguit se totum luto; et cum persicauerit lutum, insilit in ore corcodrilli, et omnia intestina eius et uiscera eicit (ed. CARMODY : 129-130).

B : Aliud animal est in Nilo fluvio, quod dicitur hydrus. Phisiologus dicit de eo quoniam satis hoc animal inimicum est crocodilo, et hanc habet naturam et consuetudinem: cum viderit cocodrillum in litore fluminis dormientem aperto ore, vadit et involvit se in limum luti quo possit facilius illabi in faucibus eius et veniens insilit in ore eius. Cocodrillus igitur desubitatus, vivum transglutit eum. Ille autem dilanians omnis viscera eius exit vivus de visceribus crocodili iam mortui ac disruptis omnibus interraneis eius (ed. CARMODY : 34 ).

A : Item est animal in Nilo ${ }^{92}$ flumine, quod dicitur ydris. Phisiologus dicit de eo quoniam satis hoc animal inimicum est corchodrillo, et hanc habere nature consuetudinem: quum viderit corchodrillum in litore fluminis dormientem aperto ore, vadit et involvit se in limum luti quo possit facilius inlabi in faucibus eius et venit insilit in ore eius. Corchodrillus vero desubitatus ${ }^{93}$, vivum transglutit eum. Ille autem dilanians omnia viscera eius et exiens ${ }^{94}$ vivus de visceribus corchodrilli iam mortui ac disruptis omnibus intraneis eius (ed. CAHIER-MARTIN, II : 122).

Lyon, B.M., 125 : [manca]

London, B.L., Royal 6.A.XI : Item aliud animal est quod in Nilo flumine est, quod dicitur ydrus. Phisiologus dicit de eo quoniam satis inimicum est crocodilo, et hanc habet naturam et consuetudinem: cum viderit cocodrillum in litore fluminis dormientem ore aperto, involvit se in limo luti quo possit facilius illabi in fauces eius et veniens insilit in os eius. Cocodrillus vero dehospitatus ${ }^{95}$, vivum transglutit eum. Ille vero dilanians omnia viscera eius exit vivus de visceribus eius crocodillo iam mortui ac disruptis omnibus interioribus (141r).

BIs : Aliud est animal in Nilo fluvio, quod dicitur idrus. Phisiologus dicit de eo quoniam satis est animal inimicum cocodrillo, et hanc habet naturam et consuetudinem: cum videt cocodrillum in litore fluminis dormientem aperto ore, vadit et involvit se in limum lutio quo possit facilius illabi in faucibus eius. Cocodrillus igitur desubitatus, vivum transglutit eum. Ille autem dilanians omnia viscera eius exit vivus de visceribus eius (ed. MANN : 52). 


\section{Vipera}

Ldnr, 8.45, De vipera : Dicit Physiologus quod vipera faciem humanam habeat usque ad umbilicum, ab umbilico vero usque ad caudam figuram cocodrilli. Meatus digestibilis quasi foramen acus dicitur et ideo non posse concipere more ceterarum bestiarum, sed tantum per os.

$Y$ : Phisiologus dicit de uipera quoniam faciem habet hominis masculus, femina autem mulieris usque ad umbilicum, ab umbilico autem usque ad caudam corcodrilli habet figuram; porro femina, non habet secretum locum, id est menbrum pariendi sinum, sed ut foramen acus habet. Si autem masculus habeat cum femina, effundet semen in os femine, et si autem creuerint filii eius in utero matris sue, non habens illa sinum unde pariatur, tunc filii adaperiunt latus matris suae, et exeunt occidentes matrem, biberit semen eius, precidet femina necessaria masculi (hoc est uirilia), et moritur masculus; cum autem creuerint filii eius in utero matris sue, non habens illa sinum unde pariatur, tunc filii adaperiunt latus matris suae, et exeunt occidentes matrem (ed. CARMODY : 110).

\section{B : [manca $]$}

A : Vipera faciem habet hominis viri masculus, femina autem mulieris usque ad umbilicum; ad umbilico autem usque ad caudam corcodrilli habet figuram. Mulier non habet in se senum, sed sicut foramen acus habent. Et si autem masculus fiat cum femina effundit semen in os femine. Et si ebiberit semen eius, precidit veneria necessaria masculi. Quum autem creverint filii eius in utero matris sue, non habens illa senum unde pariat, filii adaperiunt latus matris sue, et exeuntes uccidunt patres et matres (ed. CAHIER-MARTIN, II : 134-135).

Lyon, B.M., 125 : Vipera faciem hominis habet tam viri masculus, quam femina mulieris usque ad umbilicum; ab umbilico enim usque ad caudam corcodrilli figuram habet. Et uterus mulieris in se non habet naturam nisi ut foramen acus. Si enim masculus cupit coire cum femina, facit effundere semen in os femine, et si ea biberit semen precidit necessaria masculi a virilia et statim moritur. Cum enim creverint filii in utero eius matris sue, non habet in se naturam unde pariat tunc filii apperientes latus matris suae exeunt foras occidentes illas (194r).

London, B.L., Royal 6.A.XI : Vipera faciem hominis habet tam viri masculus, quam femina mulieris usque ad umbilicum; ab umbilico enim usque ad caudam corcodrilli figuram habet. Et uterus mulieris in se non habet sed ut foramen acus. Si enim masculus cum femina coierit, semen effundit in os femine, et si ea biberit semen precidit virilia eius et ipse statim moritur. Cum autem increverit filii in utero femine, non habet in se sinum unde pariat tunc filii aperientes latus matris suae exeunt foras occidentes matrem (142v).

BIs : [manca]

\section{Peredixion}

Ldnr, 10.29, De peredixion: Peredixion arbor est Orientis a Grecis sic dicta ex inter et circa dexteram. Fructus huius arboris, ut dicit Ysidorus, dulcis est, quo columbe mirifice delectantur, umbra vero eius et ramis proteguntur. Est autem in ipsis partibus quoddam genus drachonum volatile, quod ipsis columbis multipliciter insidiatur. Ipse autem dracho eandem arborem mirabiliter perhorrescit adeo, ut umbra illius se formidet attingi. Sedentibus ergo columbis in arbore, procul dracho insidiatur et respicit, si ulla illarum arborem deserat et sibi preda fiat. Si autem umbra arboris fuerit parte sinistra, partem dextram draco petit; si vero in parte dextra, sinistram petit. 
$Y:$ Est arbor que dicitur peridexion, inuenitur in India. Fructus autem arboris illius dulcis est totus ualde, et suauis. Columbe autem delectantur in fructu arboris illius: habitant autem in ea pascentes fructu eius. Inimicus est autem dracho columbis, timet autem arborem illam et umbram eius, in qua columbe demorantur: et non potest draco adpropiare columbis neque umbre eius. Si enim umbra arboris uenerit ad occidentem, fugit draco ad orientem; si iterum uenerit umbra eius ad orientem, fugit ad occidentem. Si autem fiet ut columba inueniatur foris arborem aut umbram eius, et inuenerit eam draco, occidit eam (ed. CARMODY : 116-117).

B : Est arbor que dicitur Indie, que dicitur Grece peritexion, latine vero circa destrum dicitur . Cuius fructum dulcis est nimis et ualde suauis. Columbe igitur satis delectantur in istius arboris gratiam: quam et de fructus eius reficiuntur et sub umbra eius requiescente ramis eius proteguntur est autem draco crudelis nimis inimicus colubarum et quantum columbe dracone timent et fugient eum, tanto plus draco illam arborem excircat et pertimescit ita ut nec umbre illius adpropinquare ausus sit sed dum insidiatur columbis ille draco ita ut capiat ex eis de longe considerat ad illam arbore et si fuerit umbra arboris a parte dextra, ille parte sinistra se facit, si autem fuerit umbra eius a parte sinistra ille fugiens eam ad dextram se facit (Montecassino, Archivio dell'Abbazia, $323: 102-103^{96}$ ).

A : Hec arbor invenitur in India, fructus autem arboris huius dulcis est totus et valde suavis; columbe autem delectantur in fructu arboris illius, habitant autem in ea fascentes <sic> fructus eius. Inimicus est autem draco columbis; timet autem arborem illam et umbram eius ubi columbe demorantur, et non potes draco appropiare arbori neque umbre eius. Si enim umbra erboris venerit ad Occidentem, fugit draco ad Orientem, si iterum venerit umbra eius ad Orientem, fugit ad Occidentem. Si autem fiat ut columba inveniatur foris arborem aut umbre sic eius, et inveniat eam draco, occidit eam (ed. CAHIER-MARTIN, II : 130-284-285).

Lyon, B.M., 125 : Hec invenitur in India, fructus enim arboris illius dulcis est totus et valde suavissimus; columbe vero delectantur in umbra arboris illius habitare et habitant in ea de fructibus enim eius bibunt. Inimicus est autem draco columbarum, sed timet autem arborem illam et umbram eius in quam columbe demorantur, et non potes adpropiare columbis neque umbre arboris. Si enim umbra eius venerit ad Occidentem, draco fugit ad Orientem, si iterum venerit umbra eius ad Orientem, fugit ad Occidentem. Et si evenerit ut columba inveniatur extra arborem aut umbram eius, occidit eam draco (194v).

London, B.L., Royal 6.A.XI : Hec arbor invenitur in India, fructus eius dulcis est totus et valde suavis; columbe vero delectantur in umbra eius et habitant in ea de fructu eius viventes. Draco etiam inimicus columbis est, et timet autem arborem illam et umbram eius in quam columbe demorantur, et non potes appropinquare draco columbis neque umbre arboris. Si enim umbra eius venit ad Orientem, draco fugit ad Occidentem, si autem ad Occidentem, fugit ad Orientem . Et si evenerit ut columba inveniatur extra arborem aut umbram eius, occidit eam draco (143r).

BIs : Arbor quedam est in partibus Indie, que grece peredixion, latine vero circa dexteram cuius fructus dulcis est nimis et valde suavis. Columbe autem satis delectantur in istius arboris gratia, quoniam de fructu eius reficiuntur et sub umbra eius requiescunt et ramis eius proteguntur. Est autem draco crudelis inimicus columbarum; et quantum columbe timent draconem et fugiunt ab eo, tantum ille draco evitat et pertimescit illam arborem, ita ut nec umbre illius appropinquare ausus sit. Set dum insidiatur columbis ille draco, ut rapiat aliquam earum, de longe considerat illam arborem. Si umbra illius arboris fuerit in parte dextera, se facit ille in parte sinistra. Si autem fuerit umbra illius in parte sinistra, ille fugiens in parte dextera se facit. Columbe autem scientes inimicum suum draconem timere illam arborem et umbram illius, et omnino nec leviter 
appropiare illi posse, ideo ad illam arborem confugiunt et ibi se commendant, ut salve esse possint ab insidiis adversarii earum. Dum ergo in illa arbore fuerint et in ipsa se continuerint, nullo modo potest eas capere draco. Si autem invenerit aliquam ex eis vel leviter segregatam ab arbore, vel extra umbram illius, statim eam rapit et devorat. Et hec quidem refert Phisiologus de columbis (ed. MANN : 66).

\section{NOTE}

1. L'articolo rivede ed approfondisce l'intervento presentato alla Giornata Internazionale di Studi "La réception du «Physiologus» dans les encyclopédies médiévales" organizzata all'Institut de recherche et d'histoire des textes di Parigi dalla Prof.ssa Draelants (14 giugno 2017). Tale contributo è stato reso durante una borsa post-doc LabEx Hastec / EPHE (2016-2017) sempre sotto la direzione della Prof.ssa Isabelle Draelants. Un particolare ringraziamento va inoltre alla Dott.ssa Emmanuelle Kuhry, che ha messo a nostra disposizione le vaste conoscenze e gli importanti risultati ottenuti durante il suo post-doc sul Physiologus: senza questi suoi preziosissimi aiuti il presente lavoro sarebbe stato molto meno particolareggiato ed approfondito.

2. La genesi e lo sviluppo di quest'opera sono molto complessi : per una panoramica su tali problematiche e un'introduzione alle versioni realizzate da Tommaso, cf. BOESE H., «Zur Textüberlieferung von Thomas Cantimpratensis' 'Liber de natura rerum' », Archivum fratrum praedicatorum, 39, 1969: 53-68; volLmANN B. K., «La vitalità delle enciclopedie di scienza naturale », in PICONE M. (dir.), L'enciclopedismo medievale, Ravenna, 1994 : 135-146 ; VAN DEN ABEELE B., « Diffusion et avatars d'une encyclopédie : le Liber de natura rerum de Thomas de Cantimpré », in DE CAllatAŸ G.,VAN DEN ABEelE B. (dir.), Une lumière venue d'ailleurs, Turnhout, 2008 : 141-176; CIPRIANI M., La place de Thomas de Cantimpré dans l'encyclopédisme médiéval: les sources du Liber de natura rerum, Tesi, Paris-Firenze, 2014, in particolare vol. 1, xiii-xx, e vol. 2, 19-34. Nonostante siano semplificative e non rendano giustizia al complesso lavoro editoriale di Tommaso, nel presente studio si manterranno per comodità le note, ma generiche, denominazioni "Thomas I" e "Thomas II" per indicare versione di partenza / più concisa e finale / più estesa del Ldnr autoriale. Per quello che riguarda il testo di riferimento, è stata usata la nostra edizione online sul sito Sourcencyme (URL < http://sourcencyme.irht.cnrs.fr >) : benché filologicamente provvisoria, essa presenta comunque un riscontro delle fonti da noi scoperte fino al 2017 (i rimandi e le citazioni del presente articolo possono essere ritrovati anche in THOMAS CANTIMPRATENSIS, Liber de naturis rerum, BOESE H. (ed.), Berlin-New York, 1973); grazie ad una borsa post-doc Von Humboldt (2018-2020) diretta dal Prof. Dr. Bernd Roling (Freie Universität Berlin), chi scrive sta inoltre finalizzando la nuova edizione critica di tali versioni autoriali. Per una discussione introduttiva sulla datazione del $L d n r$, cf. invece la bibliografia infra, n. 2. Per un'idea delle redazioni del $L d n r$ realizzate fuori dal controllo tommasiano, cf. infine scHMITz M., Le Viridarium du juriste avignonnais Jean Raynaud : une encyclopédie latine du Moyen Age tardif, Tesi, Louvain-la-Neuve, 2012 : 94-180; e vollmann B. K. (†), DEUS J., WEIGAND R. K., ULMSCHNEIDER H., Thomas von Cantimpré, Liber de naturis rerum: Kritische Ausgabe der Redaktion III (Thomas III) eines Anonymus, Wiesbaden, 2017 : 9-141.

3. Chi scrive ha ad oggi riconosciuto 137 fonti impiegate dal frate di Cantimpré : vista l'estrema complessità del suo modus scribendi, tale numero è tuttavia destinato ad aumentare. Per un'indicazione bibliografica su tale soggetto, cf. CIPRIANI, La place, 2014: vol. 2, in particolare 55-228; ID., «Un aspect de l'encyclopédisme de Thomas de Cantimpré : la section De lapidibus pretiosis du Liber de natura rerum ", Médiévales 72, 2017 : 155-174 ; ID., " Questio satis iocunda est: analisi delle fonti di questiones et responsiones del Liber de natura rerum di Tommaso di Cantimpré ", RursuSpicae, Primavera-Autunno 2017 ; e ID., «In dorso colorem habet inter viridem et ceruleum... : 
Liber rerum e osservazione zoologica diretta nell'enciclopedia di Tommaso di Cantimpré ", Reinardus. Yearbook of the International Reynard Society, 29, $2017: 16-98$.

4. Tale auctoritas è introdotta solo con le prime espansioni che condurranno poi, in diverse fasi, alla versione definitiva e più sviluppata di Thomas II. Sull'uso di questa fonte nel $L d n r$, cf. CIPRIANI, La place, 2014 : vol. 2, 40-46 e 166-168.

5. Ldnr, Prologus : "incomparabilis Augustinus [...] ; primus omnium Aristotiles [...] ; secundus est Plinius [...]; tertium autem Solinum ponimus [...]; quartus beatus Ambrosius Mediolanensis [...] magnum Basilium [...]; quintus Ysidorus episcopus [...] ; sexto loco magistrum Iacobum de Vitriaco [...] ; librum vero rerum, libellum admodum parvum $[. .$.$] ; Experimentator [...]; Galienus [...]; Platearius [...];$ Physiologus [...] ; Adelmum [...]".

6. L'importanza del Physiologus per la cultura occidentale è enorme, e la quantità di studi che lo riguardano riflette tale condizione: per una bibliografia sul soggetto si rimanda al sito The Medieval Bestiary: Animals in the Middle Ages (URL < http ://bestiary.ca >). Particolarmente utili per il presente studio sono stati : CAHIER C., MARTIN A., Mélanges d'archéologie, d'histoire et de littérature, Paris, 1851 : vol. 2-4 ; LAUCHERT F., Geschichte des Physiologus, Strassburg, 1889 ; JAMES M. R., The Bestiary, Being a Reproduction in Full of the ms. Ii.4.26 in the University Library, Oxford, 1928; SBORDONE F., « La tradizione manoscritta del Physiologus latino », Athenaeum, 27, 1949:246-280 ; MCculLocH F., Medieval Latin and French Bestiaries, Chapel Hill, 1962 ; OFFERMAnNs D., Der Physiologus nach den Handschriften $G$ und M, Meisenheim am Glan, 1966 ; KAIMAKIS D. V., Der Physiologus nach der ersten Redaktion, Meisenheim am Glan, 1974 ; ORLANDI G., « La tradizione del Physiologus e i prodromi nel bestiaro latino ", L'uomo di fronte al mondo animale nell'alto Medioevo, 7-13 aprile 1983, Spoleto, 1985 : vol. 1, 1057-1106 ; YAPP B., "A New Look at English Bestiaries ", Medium Aevum, 54, 1985 : 1-19; PAYNE A., Medieval Beasts, London, 1990 ; BAXTER R., Bestiaries and Their Uusers in the Middle Ages, Stroud, 1998; VAN DEN ABEELE B., «Un Bestiaire latin à la croisée des genres: Le manuscrit Cambridge University Library Gg.6.5 ('quatrième famille' du Bestiaire latin) », Reinardus. Yearbook of the International Reynard Society, 13, 2000 : 215-236 ; CLARK W. B., " Four Latin bestiaries and De bestiis et aliis rebus ", Bestiaires médiévaux. Nouvelles perspectives sur les manuscrits et les traditions textuelles, VAN DEN ABEELE B. (dir.), Louvain-la-Neuve, 2005 : 49-69 ; CLARK W. B., A Medieval Book of Beasts. The Second-Family Bestiary: Commentary, Art, Text and Translation, Woodbridge, 2006 ; From the Ark to the Pulpit: an Edition and Translation of the 'Transitional' Northumberland Bestiary (13th century), white C. (ed.), Louvain-la-Neuve, 2009 ; DINES I., « The Problem of the Transitional Family of Bestiaries ", Reinardus. Yearbook of the International Reynard Society, 24, 2012 : 29-52 ; STEWART P., The Medieval Bestiary and Its Textual Tradition, Tesi, Saint-Andrews, 2012 ; DINES I., "The Earliest Use of John of Salisbury's Policraticus: Third Family Bestiaries », Viator. Medieval and Reinassance Studies, 44, 1, 2013 : 107-118 ; ID., " The Bestiary in British Library, Royal MS 2.C.XII and its Role in Medieval Education ", Electronic British Library Journal, 2014 : art. 9. ; KAY S., « The English Bestiary, the Continental Physiologus and the Intersections Between Them ", Medium Aevum 85, 1, 2016 : 118-142 ; DOROFEeVA A., The Reception and Manuscript Context of the Early Medieval Latin Pre-Bestiary Physiologus, Tesi, Cambridge, 2015; KUHRY E., «Les chapitres sur les poissons et créatures aquatiques dans la tradition manuscrite du Physiologus latinus et des bestiaires latins et leur réception dans quelques encyclopédies médiévales ", in GAUVIN B., LUCAS-AVENEL M.-A. (dir.), 'Inter litteras et scientias', Recueil d'études en hommage à Catherine Jacquemard, Caen, 2019: 117-150.

7. Per un'analisi approfondita del sincretistico stilistico di Tommaso, cf. la bibliografia indicata supra, n. 3.

8. Ovvero Ldnr, 4.14, De castoribus qui fibri dicuntur; 16 , De calopo; 18 , De capra vel hirco ; 80, De onagro ; 82, De onocentauro ; 87, De panthera ; 104, De unicorni ; 5.24, De caladrio ; 36, De columba ; 45, De phoenice ; 46, De fulica ; 63, De ybicibus avibus ; 110, De strutione; 117, De huppupa ; 6.43, De serra maiori ; 45, De syrenis ; 7.19, De cethe ; 8.21, De ydro ; 45, De vipera ; 10.29, De peredixion. Dubbie sono invece le attribuzioni dei due momenti in Ldnr, 4.33, De elephante ("Dicitur quod nisi fructu 
mandragore vescatur, femina non queat concipere. Femina paritura profundum stagnum ingreditur; nam si fetus in terra caderet, surgere non valeret"), e 39, De erinacio ("Est autem animal spinosum formam porcelli habens"). Tali excerpta, infatti (1) sono impiegati anonimamente e (2) riportano contenuti trasmessi in maniera estremamente simile anche da altre fonti tommasiane (Giacomo da Vitry, Isidoro, Plinio, la Glossa,...) : in altre parole, considerando questi due passaggi, non è possibile dire con precisione da quale di queste auctoritates siano stati ricopiati.

9. $L d n r, 10.29$, De peredixion; e 5.36, De columba. Salvo dove ritennuto necessario, per il testo dei passaggi indicati, si rimanda sempre, implicitamente, a infra, § Tabella 2. Per alcuni esempi di ripetitività tommasiana, cf. i capitoli su Aristotele, Basilio e la Bibbia in CIPRIANI, La place, 2014 : vol. 2, 68-73, 82-85 e 88-90; tutto ciò è inoltre sviluppato dal frate con l'introduzione delle sezioni medico-pratiche che caratterizzano Thomas II : cf. infra, n. 14.

10. Cf. ad esempio Ldnr, 4.80, De onagro ; 5.24 , De caladrio ; e 5.45, De phoenice. Per essere ancora più chiari : considerando la nostra trascrizione del Liber, i passi del Physiologus superano difficilmente i 1700 caratteri.

11. Ldnr, 4.16, De calopo ; 6.43, De serra maiori ; 10.29, De peredixion.

12. Per informazioni in merito, cf. CIPRIANI, La place, 2014: rispettivamente vol. 1, cvi, cxiii e cxvii, e vol. 2, 68-74, 145-147 e 183-189.

13. Per dati sull'uso di Marbodo, cf. CIPRIANI, «Questio satis iocunda est », 2017 ; per informazioni su quello di Onorio cf. invece ID., La place... : vol. 1 : cxii, e vol. $2: 130-132$. Salvo un breve accenno in CIPRIANI M., «Si vero ex amore vel tristitia vel ira... : emozioni, sentimenti e stati d'animo nel Liber de natura rerum di Tommaso di Cantimprè », in BAKER C., CAVAGNA M., CLESSE G. (dir.), Entre le cour et le diaphragme. (D)écrire les émotions dans la littérature narrative et scientifique du Moyen Âge, Louvain-la Neuve, 2018 : 35-48, le informazioni su Ferrario sono qui discusse per la prima volta, e derivano da una comparazione delle sezioni tommasiane con l'edizione: FERrARIUS, Curae, GIACosA P. (ed.), in Magistri Salernitani nondum editi, GIACOSA P. (ed.), Torino, $1901: 1-68$.

14. Per una comparazione quantitatistica fra le opere di Beda e il Physiologus, cf. CIPRIANI, La place, 2014 : vol. 2, 224.

15. Esempi di altre opere usate in questo modo in Thomas I sono l'Historia Scholastica o il De naturis et virtutibus aquarum. Quanto a Thomas II, auctoritates usate da Tommaso come complemento al cuore dei vari capitoli sono ad esempio l'anonima Tereoperica e l'Herbarium Apuleii Platonici. Per un approfondimento sull'uso di Pietro Comestore e Dioscoride, cf. CIPRIANI, La place, 2014 : vol. 2, 169-170 e 98. Quanto alle due fonti mediche, tali informazioni sono qui presentate per la prima volta e saranno discusse approfonditamente in uno specifico articolo sulla medicina tommasiana che stiamo preparando. Una prima bozza di tale lavoro è comunque stata esposta, con il titolo "Between Preaching and Medicine. A Practical Medical Education for Friars: the Case of Thomas de Cantimpré's Liber de Natura Rerum", alla Conferenza "Angelical Conjunctions: Crossroads of Medicine and Religion, 1200-1800" (Montreal: McGill University, 12-14 aprile 2019).

16. Sulle auctoritates impiegate in più redazioni del Ldnr, cf. supra, n. 14, CIPRIANI, "Questio satis iocunda est ", 2017.. Cercando invece di chiarire quando viene introdotto il Physiologus, è per ora possibile dire che è stato impiegato solo nello stadio basico del Ldnr. Cf. supra, n. 2, e infra, n. 64 .

17. Per quello che concerne le informazioni personali o anonime, si hanno in $L d n r, 4,14$, De castoribus qui fibri dicuntur, e in 6.45, De syrenis. Quanto alle sezioni moralizzanti sono in Ldnr, 5.38, De columba; 110, De strutione; 117, De huppupa; e 10.29, De peredixion; le parole di Aimone completano invece il Physiologus in Ldnr, 5.45, De phoenice, mentre una questio salernitana è inserita, in Thomas II, fra l'excerpta del trattatello e quello di Experimentator, in 110, De strutione. L'uso di Aimone di Halbertstadt è analizzato in CIPRIANI, La place, 2014: vol. 2, 127-128, mentre quello delle questiones in ID., "Questio satis iocunda est ", 2017. Per informazioni sulle conoscenze personali di Tommaso, cf. CIPRIANI, «In dorso colorem », 2017 : in particolare 59 e segg. ; sulle sezioni morali nel Ldnr, cf. invece RIBÉMONT B., "L'animal comme exemple dans les encyclopédies médiévales: 
morale et 'naturalisme' dans le Livre des propriétés des choses ", L'animal exemplaire au Moyen Âge, $V^{e}$ XV $V^{e}$ siècles, BERLIOZ J., POLO DE BEAULIEU M.-A. (dir.), Rennes, 1999: 191-205; VAN DEN ABEELE, "L'allégorie animale dans les encyclopédies latines du Moyen Âge ", L'animal exemplaire, 1999 : 123-143 ; e CIPRIANI, La place, 2014 : vol. 2, 50-51.

18. Su tale opera, cf. infra, n. 32 .

19. Cf. ad esempio Ldnr, 10.29 De peredixion, e il Physiologus BIs, 33, De columba et de dracone et umbra arboris (l'edizione usata qui è : "Physiologus Latinus, versio BIs ", MANN M. F. (ed.), in MANN M. F. (ed.), Der 'Bestiaire Divin' des Guillaume le Clerc, Heilbronn, 1888 : 66). Per un discorso preciso sulla versione del Ldnr impiegata da Tommaso, cf. infra, § Il Physiologus sulla scrivania di Tommaso, e § Conclusioni.

20. Ovvero Ldnr, 4.14, De castoribus qui fibri dicuntur ; 87, De panthera ; 46, De fulica ; 117, De huppupa. Altri esempi di questa metodologia di impiego si possono vedere in $L d n r, 4.16$, De calopo ; 18, De capra vel hirco ; 80, De onagro ; 82, De onocentauro ; 5.63, De ybicibus avibus ; 110, De strutione ; 6.43, De serra maiori ; 7.19, De cethe; 8.21 , De ydro; 45, De vipera. Come dimostra la ripetizione, in questi elenchi, di alcuni animali, le informazioni che Tommaso riprende da questa fonte possono a volte essere "miste".

21. Ldnr, 5.110, De strutione ; 6.45, De syrenis ; 8.45 , De vipera.

22. Ldnr, 4.104, De unicorni ; 5.24, De caladrio ; 36, De columba ; 45, De phoenice ; 10.29, De peredixion.

23. Tutto questo avviene nel $38 \%$ dei casi ; interessante poi notare come la percentuale di citazione si abbassi al $15 \%$ nei rimandi zoologico-naturalistici e allo $0 \%$ in quelli medico-pratici di Thomas II. Per un'analisi della questione e del modus scribendi di Tommaso, cf. CIPRIANI, La place, 2014 : vol. 2, 40-45.

24. Ciò avviene in circa il $2 \%$ delle citazioni complessive. In tal senso si consideri ad esempio che il frate di Cantimpré rimanda a Solino in 107 occasioni, ma solo in 6 momenti tale riferimento è scorretto, e richiama in realtà Plinio o Isidoro. Per un'analisi più approfondita di questi dati ed altri esempi, cf. CIPRIANI, La place, 2014 : vol. 2, 201-212, 132-135 e 68-74. In questo contesto va inoltre accennato il caso particolare di $L d n r, 13$, De fontibus : molte delle attribuzioni di questo libro sono infatti completamente sbagliate; per un'analisi della questione, cf. CIPRIANI, "In dorso colorem ", $2017:$ 43-44, anche n. 88-89-90.

25. Ovvero in Ldnr, 4.16, De calopo ; 87, De panthera ; 6.45, De syrenis ; 8.45, De phoenice ; 117, De huppupa. Cf. Anche infra, § Conclusioni.

26. In $L d n r, 4.14$, De castoribus qui fibri dicuntur ; 18, De capra vel hirco ; 82, De onocentauro ; 104, De unicorni ; 5.46, De fulica ; 63, De ybicibus avibus.

27. Ciò avviene in Ldnr, 4.80, De onagro ; 5.24, De caladrio ; 36, De columba ; 45, De phoenice; 110, De strutione ; 6.43, De serra maiori ; 7.19, De cethe ; 8.21, De ydro ; 10.29, De peredixion. In Ldnr, 7.19, De cethe, l'attribuzione errata è doppia: dopo il paragrafo derivato dal Physiologus, Tommaso cita infatti Basilio e ripete l'errore precedente dicendo : "Magnus Basilius idem dicit quod Ysidorus".

28. L'enciclopedia dell'arcivescovo di Siviglia è infatti conservata in quasi 500 manoscritti dalla tradizione intricata. Cf. ANSPACH, A. E., " Das Fortleben Isidors im VII. bis IX. Jahrhundert ", Miscellanea Isidoriana. Homenaje a S. Isidoro de Sevilla en el XIII Centenario de su muerte. 636-4 de abril1936, Roma, 1936 : 323-356 ; CATON F., Las Etimologías en la tradición manuscrita medieval estudiada por el Dr. Anspach, León, 1966 ; ma, soprattutto, cf. VAN DEN ABEELE B., « La tradition manuscrite des Etymologies d'Isidore de Séville ", in ELFASSI J., RIBÉMONT B. (dir.), La réception d'Isidore de Séville durant le Moyen Âge tardif (XIIe - XVe s.), Paris, 2008 : 195-208. Per una breve discussione sulle Etymologie con interpolazioni dal Physiologus, cf. invece CARMODY F. J., « De Bestiis et Aliis Rebus and the Latin Physiologus », Speculum, 13, 2, $1938: 153-159$.

29. Ovvero : Basel, Universitätsbibliothek, F III 15 ; München, Bayerische Staatsbibliothek, Clm 6250 ; Paris, Bibliothèque nationale de France, Lat. 425 ; Paris, B.n.F., Lat. 426; St. Gallen, Stiftsbibliothek, Cod. Sang. 236. Le edizioni consultate sono invece: ISIDORUS HISPALENSIS, 
Etymologiarum sive Originum libri XX, LINDSAY W. M. (ed.), Oxford, 1911, 2 voll.; ID., Etimologías. Edición bilingüe, oROZ RETA J.-CASQUero M.-A. M.-DÍAZ Y DÍAZ M. C. (ed.), Madrid, 2004 ; e ID., Etymologiae XII : des animaux, ANDRÉ J (ed.), Paris, 1986.

30. Cf. ad esempio Ldnr, 5.92 De serra maiori : "Serra marina belua est, ut Ysidorus dicit, corpore ingens pennasque habens latissimas et alas immanes. Hec bestia cum viderit navem velificantem in pelago, elevat alas suas super aquas et in contrarium navis velificare contendit. Cumque stadiis triginta vel etiam quadraginta aliquando hec conata fuerit nec prevaluerit, tandem laborem non sustinens deficit, deponensque pennas suas ad se retrahit. Fluctus vero lassam reportat ad locum pristinum in profundum maris"; Etymologie, 12.6.16: "Serra nuncupata, quia serratam cristam habet, et subternatans navem secat" (ed. LINDSAY); e Physiologus BIs, 4, De serra: "Est belua in mari que dicitur serra, pennas habens immanes. Hec cum viderit in mare navem velificantem, elevat pennas suas et contendit velificare cum nave. Ubi autem contendit currere contra naves stadiis triginta vel quadraginta, laborem non sustinens deficit, et deponens pennas, ad se trait eas; unde vero maris iam lassum reportant eum ad pristinum locuum suum in profundum" (ed. MANN : 39). Un altro esempio significativo si ha con il passo già citato sull'albero Peredixion : tale pianta non è infatti nominata nelle Etymologie, ma è presente nel Physiologus. Sulla versione di quest'opera usata da Tommaso, si veda la discussione infra.

31. Per una spiegazione approfondita si tali differenze, cf. la bibliografia menzionata supra, n. 5 .

32. Sulla datazione del Ldnr, cf. supra, n. 1; sulla sua complessa tradizione cf. infra, n. 64. Per un'analisi delle zone in cui si spostò Tommaso durante la redazione del Ldnr e le lingue da lui conosciute, cf. invece CIPRIANI, « In dorso colorem », $2017: 62-64$, anche n. 145, e 70.

33. Questa categorizzazione rispetta l'ordine cronologico condiviso dalla maggior parte degli studiosi. Come è evidente, essa non comprende tuttavia solo i Physiologus stricto sensu, ma anche molti bestiari da esso derivati : per tale, intelligente categorizzazione si è seguito l'articolo di KAY, "The English Bestiary, the Continental Physiologus ", 2016; ad ogni modo, salvo specifiche indicazioni, nel presente articolo si userà sempre il titolo "Physiologus" per indicare genericamente tutti i testi trattati. Le edizioni e i manoscritti usati per tali comparazioni sono stati i seguenti : per la versio $Y$ : «Physiologus Latinus, versio $Y$ », CARMODY F. J. (ed.), University of California Publications in Classical Philology, 12, 7, 1941 : 95-134; versio C : Wolfenbüttel, Gud. lat. 148: 98v-109v; Physiologus Bernensis, voll-Faksimile aus des Codex Bongarsianus 318 der Bürgerbibliothek Bern, VON STEIGER C., HOMBURGER O. (ed.), Basel, 1964; versio B: Bern, Bürgerbibliothek, 233 : 1-13 ; Montecassino, Archivio dell'Abbazia, 323 ; Oxford, Bodleian Library, Auct. T.2.23; e Physiologus Latinus, versio B, CARMODY F. J. (ed.), Paris, 1939 (su questo testo, cf. anche infra,); versio $A$ : Rouen, Bibliothèque Municipale, 638, f. 232-242 ; e CAHIER, MARTIN, Mélanges d'archéologie, 1851 : vol. 2, 85-100 e 106-232 ; vol. 3, 203-288 ; vol. 4, 55-87 (Bruxelles, Bibliothèque Royale, KBR 10074: 140v-156v, precedentemente visto online al sito Belgica < URL: https:// belgica.kbr.be/belgica/ >, è stato recentemente tolto da tale piattaforma, e non è stato quindi possibile effettuare un ulteriore controllo durante la redazione del presente articolo); Dicta Chrysostomi : « Dicta Chrysostomi », vON HEIDER G. (ed.), (Physiologus : nach einer Handschrift des XI. Jahrhunderts), Wien, 1851 ; versio BIs : Oxford, Bodleian Library, Laud Misc. 247 ; Paris, B.n.F., Nouv. acq. lat. 873 ; Città del Vaticano, Biblioteca Apostolica Vaticana, Pal. lat. 1074 ; e « Physiologus Latinus, versio BIs ", MANN M. F. (ed.) (MANN M. F., Der 'Bestiaire Divin'), Heilbronn, 1888 : 37-73 ; Physiologus Theobaldi : THEOBALDUs, Theobaldi Physiologus, EDEN P. T. (ed.), Leiden-Köln, 1972 ; versio H-BIs : Cambridge, Corpus Christi College, 22 : 162-169; e London, British Library, Stowe 1067 : $1-15 \mathrm{v}$; Aviarium : HUGO DE FOLIETO, Aviarium : The Medieval Book of Birds. Hugh of Fouilloy's 'Aviarium', CLARK W. B. (ed.), New York, 1992 ; Bestiari di "seconda famiglia": CLARK, A Medieval Book of Beasts, 2006 ; e London, B.L., Harley 3244 ; Bestiari di "transizione" : From the Ark to the Pulpit, white C. (ed.), 2009 ; London, B.L., Royal 12.C.XIX : 1-94; e Los Angeles, Getty Museum, $100: 1$-73 ; bestiari versio $H$ : Chalon-sur-Saône, Bibliothèque municipale, 14 : 55-89 ; Paris, B.n.F., Lat. 14429 : 109v-118 ; ma anche De bestiis et aliis rebus, liber II, MIGNE J.-P. (ed.), (Patrologia latina cursus completus), Paris, 
1844-1855 : vol. 177, 56-83 ; Bestiary di "terza famiglia" : Cambridge, Fitzwilliam Museum, 254 : 148 ; per tutto sono stati consultati anche i Bestiari medievali, MORINI L. (dir.), Torino, 1996. Vista la loro natura, nel nostro esame non sono invece stati considerati : (1) il Glossarium Ansileubi : infatti, sebbene incorpori 22 passaggi del Physiologus, quest'opera non si può considerare una redazione del trattatello didattico (per una bibliografia in merito, cf. McculLoch, Medieval Latin and French Bestiariesi, 1962 : 24-25, e «Excerpta ex antiquissimo libro Physiologo », in MAI A., (Classici Auctores), Roma, 1835 : vol. 7, 589-596) ; (2) il bestiario di "IV famiglia" : tale redazione riprende a sua volta le enciclopedie ed è quindi più tardiva (per un analisi di tale opera, cf. VAN DEN ABEELE B., "Un Bestiaire latin à la croisée des genre ", 2000). Un ulteriore confronto con le versioni prese in esame è stato infine permesso grazie alle tabelle comparative generosamente messe a disposizione dalla Dott.ssa Kuhry.

34. Per un inquadramento sulle traduzioni e i rimaneggiamenti volgari del Physiologus, cf. soprattutto MCCULlOCH, Medieval Latin and French Bestiaries, 1962; KAY, " The English Bestiary, the Continental Physiologus ", 2016; MURATOVA X., « Le Bestiaire médiéval et la culture normande ", Manuscrits et enluminures dans le monde normand: Xe-Xve siècles: colloque de Cerisy-la-Salle, octobre 1995, Caen, 1999 : 151-166 ; e MORTON J., « The Book of the World at an Anglo-Norman Court : The Bestiaire de Philippe de Thaon as a Theological Performance ", in ASHE L., LAWTON D., SCASE W. (dir.), New Medieval Litterature, 16, Cambridge : 2016 : 1-39. Per le nostre analisi sono state usate le edizioni : PIERRE DE BEAUVAIS, Bestiaire de Pierre de Beauvais, version courte, MERMIER G. R. (ed.), Paris, 1977 ; PHILIPPE DE THAON, Bestiaire, WALBERG E. (ed.), Paris, 1900 ; e ID., Bestiaire, MORINI L. (ed.), Paris, 2018 ; GERVAISE, « Le bestiaire de Gervaise », MEYER P. (ed.), Romania, 1, 1872 : 420-443 ; GUILLAUME LE CLERC, Le Bestiaire Divin de Guillaume Clerc de Normandie, HIPPEAU C. (ed.), Caen, 1852 ; e Der 'Bestiaire Divin', 1888.

35. Cf. Ldnr, 14.11, De berillo: "Berillus, si formam sexangularem habuerit, archus celestis colores efficit in radio Solis, qui, etiam si rotunde forme fuerit velut pomum humectatus aqua, in claritate Solis mortuos carbones vel pannum laneum nigrum vel bullituram, arboris siccam accendit. Unde quidam egregie satis versificans dixit in persona lapidis berilli: Me dedit insignem virtus que format in ignem / Solis splendorem, non ignis passa calorem / Sic lux eterna descendit ab arce superna / Est incarnata, non matre tamen violata", e Philippe de Thaon, Bestiaire, v. 3083-3090 e 3093-3100 : "Li beriz at vertu en sei. / Le rai del soleil trait a sei et li raiz est de tel nature / Le beril passe senz frainture; / E li chalz est de l'altre part, / Que il esprent et bruille et art/ Estupes, tundre, drapelez, / Sèches chosetes, estramez ; / [...] Icil beriz nus signefie / Nostre Dame Sainte Marie, / Par le soleil Dé entendum / E par le rai sun fiz pernum ; / Kar si cum li raiz de soleil / A ceste pierë est feeil, / Qu'il entre en li senz uverture / E ultre passe senz frainture" (ed. WALBERG : 111-112 ; ed. MORINI : 223). In tal senso non è comunque ancora chiaro se il brabantino abbia (1) tradotto di suo pugno il testo anglo-normanno (si noti che Tommaso afferma chiaramente "Unde quidam egregie satis versificans dixit in persona lapidis berilli"), (2) ricopiato una fonte latina in versi impiegata anche dal poeta di Thaon, o (3) usato una traduzione latina del Bestiaire di Filippo (un esempio di simili rimaneggiamenti si ha nel ms. London, British Library, Arundel $342: 71-78$, che riporta una versione latina del Lapidaire del poeta di Thaon: il testo è stato visionato nella trascrizione presente in «Les plus anciens lapidaires français ", MEYER P., Romania, 38, 1909 : 539-552). Per un'analisi di questo passaggio e del suo rapporto con i lapidari dello stesso autore, cf. CIPRIANI, « Un aspect de l'encyclopédisme de Thomas de Cantimpré », 2017 : 167-168, in particolare n. 67-68-69 ; su questi passaggi e la loro circolazione, cf. anche MORINI, Bestiaire : 44-50.

36. Per tutte le comparazioni di questo tipo, cf. infra, § Tabella 1: "macro-" contenuti Ldnr / Physiologus. I dati forniti in questa occasione tengono sempre conto della versione più ampia / con il maggior numero di capitoli di un testo: le sezioni di un'opera possono infatti variare leggermente anche fra i loro stessi testimoni. 
37. Cf. Ldnr, 5.61, De garrulo: "De una in aliam garriendo transit nec vix quisquam illam transire potest quem non garriat. Ceterarum avium voces vel modulos non ad delectamenta letitie, sed ad garriendum dicitur imitari", e Aviarium, 50, De graculo: "de una arbore in aliam garriendo transit, quia garrulus homo, de his cum quibus habitat, etiam turpia quae de his noverit aliis narrare non cessat" (ed. CLARK: 220) ; Ldnr, 5.91, De nicticorace: "Noctue carnes paraliticos iuvant”, e Aviarium, 39, De nycticorace: "Cum enim leprosum curaret" (ed. CLARK : 172) ; e Ldnr, 5.97, De pellicano : "Philosophus : Hec avis semper macie inficitur et, quicquid glutit, cito digerit, quia venter eius nullum diverticulum habet qui cibum teneat; solum enim visceris ductum habet qui ab introitu oris usque ad nature secreta pertingit", e Aviarium, 39, De pelicano: "Huius etiam volucris natura talis dicitur esse quod semper afficitur macie, et quicquid glutit cito digerit, quia venter eius nullum habet diverticulum in quo retineat cibum. Non igitur cibus ille corpus impingat, sed tantum sustinet et confortat" (ed. CLARK : 170).

38. Per un esempio, cf. Ldnr, 6.43, De serra maior: "Serra marina belua est [...] corpore ingens pennasque habens latissimas et alas immanes. Hec bestia cum viderit navem velificantem in pelago, elevat alas suas super aquas et in contrarium navis velificare contendit", e bestiari di "transizione" : "est belva in mari qui dicitur serra pennas habens immanas. Hec cum viderit navim in pelago velificantem, elevat pennas suas super aquam et contendit velificare contra navim" (Los Angeles, Getty Museum, MS 100 : $46 v)$.

39. La scelta di limitare il numero degli esempi è dovuta alla volontà di evitare - per quanto possibile - la prolissità . Importanti casi analoghi si possono comunque vedere nella maggior parte dei lemmi, ma soprattutto nei paragrafi su mangusta, onocentauro, upupa, sirene e pesce sega. Per una visione d'insieme, cf. ancora una volta infra, \& Tabella 1.

40. Ldnr, 5.45, De phoenice.

41. Cf. Dicta Chrysostomi, 27 : "De ea dicit Phisiologus quia expletis quingentis annis vite sue intrat in lignum Libani repletque ambas alas suas diversis aromatibus ejusdem ligni, faciensque variis de pigmentis clausum nidum, congregat sarmentorum acervum maximum subter domum poneus. Accedensque ad aerem solis ignem trahit secum et iucendit sarmenta ac ingreditur in nidum suum, mense Faminoth id est Martio, et comburit se ipsam, et cinis prima die vertitur in vermem, secunda die in volucrem. Tercia vero die revocatur in pristinum statum" (ed. HEIDER : 44-45); bestiari H-Bis, De fenice: "Est autem singularis in toto mundo hec quingentos annos vivere fertur et ultra dum se viderit seus se collectis virgultis rogum sibi instruit et contra radios solis alarum prolausu volitans incendium nutrit seque urit. Postea vero tertia die nova avis de cineribus surgit" (Cambridge, Corpus Christi College, $22: 166 \mathrm{v}$ ) ; bestiari "di seconda famiglia", De fenicis combustione: "Hec quingentos ultra annos vivens dum se viderit senius se collectis aromarticis virgultis rogum sibi instruit et conversa ad radium solis alarum plausu voluntarium sibi nutrit incendium seque urit. Postea vero die nona avis de cineribus suis surgit" (London, B.L., Harley 3244 : $53 \mathrm{v})$; bestiari di "transizione" : "Hec quingentos et ultra annis vivens dum se viderit senuisse collectis virgultis rogum sibi instruit et contra sol radios alarum plausu volitans sibi incendium nutrit seseque urit sicque iterum tertia die de cineribus suis resurgit" (London, British Library, Royal 12.C.XIX : 50r). L'assenza di riferimenti ad Eliopoli nei bestiari di "seconda famiglia" è evidenziata anche da Clark, A medieval book of beasts, $2006: 81, \mathrm{n} .118$.

42. Sulle particolarita dei bestiari "di terza famiglia" e dei loro testimoni, cf. DINES I., « The Earliest Use of John of Salisbury's Policraticus ", 2013.

43. Cf. Ldnr, 4.104, De unicorni, e Philippe de Thaon, Bestiaire, v. 399-415: "Si vent hom al forest / ù sis repairs est; / met une pucele / hors de sein sa mamele, / E par odurement / monosceros la sent ; / Dunc vent la pucele, / e si baiset sa mamele, / En sun devant se dort, / issi vent sa mort ; / Li hom survent atant, / ki l'ocit en dormant, / U trestut vif le prent, / si fait puis sun talent." (ed. WALBERG : 15-16 ; ed. MORINI : 141).

44. Cf. Le Bestiaire Divin..., De la sereine, 12, v. 995-1054 (ed. HIPPEAU : 224-226).

45. L'opera attribuita al piccardo circolò in due versioni : una corta, redatta fra il 1180 e il 1206, e una lunga, composta invece fra il 1246 e il 1268. Osservando tali datazioni, quest'ultima è stata 
subito esclusa dalla lista delle possibili fonti tommasiane in quanto non poteva circolare nel periodo in cui il frate redasse la prima fase del $L d n r$, ovvero - come è già stato detto più volte fra 1225 e 1242 ca. (cf. supra). Per le datazioni del Bestiaire piccardo, cf. BAKER C., « De la paternité de la version longue du Bestiaire attribuée à Pierre de Beauvais ", Bestiaires médiévaux, 2005 : 1-29 ; e PIERRE DE BEAUVAIS, Le bestiaire : version longue attribuée à Pierre de Beauvais, BAKER C. (ed.), Paris, 2010: in particolare 14-17 e 29-30. Per altre idee sulla figliazione dei due testi, cf. invece MCCULloch, Medieval Latin and French Bestiaries, 1962: 62-69; e MERMIER G. R., A Medieval Book of Beasts: Pierre de Beauvais' Bestiary, Lewiston (NY) : 1992; ma anche VAN DEN ABEELE B., "Deux manuscrits inconnus du Bestiaire attribué à Pierre de Beauvais ", Bestiaires médiévaux, 2005 : 183-199.

46. Cf. Ldnr, 5.45, De phoenice, e Bestiaire de Pierre de Beauvais: "La fenis converse en Inde. De lui dit Phisiologes que quant il a vescu. V. cens anz, il entre les arbres qui sont apelé liban et illuec raemplit ses eles de douces odors des vergeles des libans qu'il en aporte et fait au mois de marz ou d'avril I estruit de feu et puis volete entour l'estruit encontre le soulail si que li estruiz esprent par le voletement de ses eles et aisni s'art ilueques et de la cendre renaist il meismes au tierz jor touz noviaus." (ed. MERMIER : 65-66).

47. Cf. Ldnr, 5.46, De fulica, i corrispettivi passaggi dei vari Physiologus (in particolare i termini "intelligibile et prudentissimum, super omnia volatilia", "cadaveribus non vescitur", "commoratur", "escam suam"), e : Bestiaire di Filippo, v. 2749-2764 : “... oisel entendable, / E cointes e membrez, / humles et atemprez, / E de honeste pulture; / de caruine n'ad cure ; / E cel lui volt maneir, / il pais pot aveir, / S'i ad viand e pais, / n'en turnerat jamais" (ed. WALBERG : 99-100; ed. MORINI : 213) ; e Bestiaire Divin, De la fullica, 23, v. 1883-1901: "Or vos conterai d'un oisel / Qui moult par est corteis et bel. / Toz dis est en eve manable / Et moult sage et moult entendable. / En cez estans ades sejorne, / En mi l'eve son ni atorne, / Ou entre pierres en la mer, / Ou nus homne puet habiter. / Toz jorz est assiduelment / En une place solement ; / Nule feiz ne s'en quiert moveir, / Quer tot $i$ a son estoueir / Et ne porquant, quant ele sent / Que il deit estre aucun torment / Donc s'en vait en l'eve baignier, / Et deduire et esbaneier / Puis se remet en sa meson / Toz jorz men jue boen peisson, / De nule charungne ne vit" (ed. HIPPEAU : 254-255); e Bestiaire de Pierre de Beauvais: "Uns oisiaus est qui est apelé fulica. Cist oisiaus est entendanz et sages desor touz oisiaus. Il ne goute de charoigne ne nuliu ne vole, ainz demore de ci en la fin en I seul lieu et ileuc a sa viande." (ed. MERMIER : 65-66). Come detto supra, n. 35, il dubbio che Tommaso abbia tradotto dall'anglo-normanno rimane invece per il berillio.

48. La critica è concorde nel sostenere che (1) Filippo di Thaon abbia usato un Physiologus BIs, ma sia stato anche influenzato dai Dicta Chrisostomi, (2) Gervasio si sia basato su una copia dei Dicta, e (3) Guglielmo abbia invece impiegato un Physiologus BIs (oltre agli studi citati in precedenza, per un excursus sulla questione, cf. SMEETS J. R., « L'Ordre des Animaux dans le Physiologus de Philippe de Thaon et la prétendue préséance de la perdrix sur l'aigle », Revue Belge de Philologie et d'Histoire / Belgisch Tijdschrift voor Filologie en Geschiedenis, 40, 1962: 798-803; HENKEL N., Studien zum Physiologus im Mittelalter, Tübingen, 1976 ; EVDoKimova L., « Deux traductions du Physiologus: le sens allégorique de la nature et le sens allégorique de la Bible », Reinardus. Yearbook of the International Reynard Society, 11, 1998: 53-66; e KAY, "The English Bestiary, the Continental Physiologus ", 2016 : in particolare 128-132). La questione è più delicata per quanto riguarda invece Pietro di Beauvais : secondo Mcculloch F., Medieval Latin and French Bestiaries, 1962: in particolare 29, e MERMIER G. R., « De Pierre de Beauvais et particulièrement de son Bestiaire : Vers une solution des problèmes ", Romanische Forschungen, 78, 2/3, 1966 : 338-371, in particolare 352, anche il piccardo avrebbe infatti usato una qualche versione BIs; sebbene non sia stato possibile visionare il testo BIs presente nel ms. Tours, Bibliothèque Municipale, 312 - che KAY, « The English Bestiary, the Continental Physiologus ", $2016: 123$, ritiene "the likely model of the short version of the Bestiary of Pierre -, questo riconoscimento sembra in qualche modo dubbio: come accennato supra, la voce "ibrida" sulla fenice presente nel Bestiaire piccardo sembra invece suggerire che Pietro abbia usato piuttosto una versione latina "intermedia" fra $B, A$ e $Y$, più che una 
"convenzionale" come BIs (per un esempio di questa ibridazione e una discussione in merito, cf. infra, anche i passaggi del ms. London, B.L., Royal 6.A.XI nella Tabella 2). Sempre per sottolineare una somiglianza fra la fonte tommasiana e quella delle redazioni volgari considerate, è interessante inoltre notare che le opere di Filippo, Guglielmo e Pietro riportano un testo sulla sirena molto simile a quello di $L d n r, 6.45$, De syrenis : al pari dell'opera di Tommaso (dove si dice : "a capite usque ad umbilicum figuram mulieris"), tali testi sottolineano infatti una somiglianza fra la creatura marina e la donna (rispettivamente: v. 1361-1369,: "de femme ad faiture / entresque la ceinture”, ed. WALBERG : 51 ; v. 997-999 : “...des la cainture en amont / Est la plus bele riens del mont / En guise de feme formee", ed. HIPPEAU : 224 ; e "la serain porte semblance de fame de ci au nobril", ed. MERMIER: 68); un passo analogo è inoltre presente in un'altra opera latina indebitata con il Physiologus e legata al Ldnr, ovvero l'anonimo Liber monstrorum (che riporta: "a capite usque ad umbilicum sunt a corpore virginali"; il testo è stato consultato in ed. "Liber monstrorum ", ORCHARD A. (ed.), (Pride and Prodigies. Studies in the Monsters of the Beowulf-Manuscript), Toronto-BuffaloLondon, 1995 : 254-317, qui 262 ; sul rapporto di quest'opera con il Ldnr, cf. CIPRIANI, La place, 2014 : vol. 2, 59-63) ; come si può vedere infra, Tabella 2, tutte le versioni latine del Physiologus che sono state consultate parlano invece di una somiglianza generica con l'uomo ("a capite usque ad umbilicum figuram hominis"), e si può quindi pensare all'esistenza di una redazione del trattatello in cui si parla di corpo femminile invece di un generico "di uomo" (cf anche il ms. Oxford, Bodleian Library, Laud. Misc. 247, f. 147r).

49. Vista questa somiglianza, è necessario spiegare rapidamente le caratteristiche di tali versioni del Physiologus. Y compare nell'VIII sec., trascrive con precisione una versione greca $\Pi$ - di cui conserva anche alcuni termini - e riporta nella sua copia più estesa 49 capitoli. La versio $B$ ha un'origine poco chiara, ma emerge nel IX sec., è corredata da un nuovo incipit e contiene al massimo 36 capitoli : essa sarà la base di tutti i Physiologus e bestiari che si svilupperanno dall'XI sec.. A compare nel X sec., è formata al massimo da 36 capitoli e fonde senza apparente logica sezioni di Y e B. Il bestiario "di prima famiglia" / BIs nasce infine nel X-XI sec. dall'unione di materiale ricavato da $B$ con quello di una versione sui generis delle Etymologie : tali aggiunte sono solitamente inserite alla fine delle voci dopo un preciso marker di citazione. Su tutta la questione, cf. Mcculloch, Medieval Latin and French Bestiaries, 1962: in particolare 22-30, e KUHRY, " Les chapitres sur les poissons ", 2019. Per un ulteriore chiarimento sul rapporto fra versioni latine e greche, cf. SBORDONE, « La tradizione manoscritta del Physiologus latino », 1949. Per la definizione di Etymologie "sui generis" e le loro caratteristiche, cf. invece DINES, "The Problem of the Transitional Family of Bestiaries », $2012: 31$ e segg.

50. In $Y$ si ha : "preicidere", "si cum dolo veniant, vel cum amicitia", "ilico dormit in fovea", "prudens"; mentre in Ldnr, 4.16, De calopo ; 18, De capra... ; 87, De panthera, e 5.46, De fulica: "secando", "venatores aut viatores", "recondit se in spelunca sua", "intelligibile et prudentissimum".

51. Cf. Ldnr, 6.43, De serra maiori, e versio A.

52. A riporta: "et umbram eius ubi columbe demorantur, et non potes draco appropiare arbori neque umbre eius. Si enim umbra erboris venerit ad Occidentem, fugit draco ad Orientem, si iterum venerit umbra eius ad Orientem, fugit ad Occidentem", mentre in Ldnr, 5.36, De columba, si ha: "Si autem fuerit umbra parte sinistra, dextram dracho petit, si dextra sinistram" (in 10.29, De peredixion, il testo viene modificato in : "Si autem umbra arboris fuerit parte sinistra, partem dextram draco petit; si vero in parte dextra, sinistram petit").

53. Per quello che concerne le locuzioni su antilope, capra, pantera e folaga, B e BIs riportano: "secare" "venatores sunt an viatores", "recondit se in speluncam suam", "intelligibile et prudentissimum", mentre in Ldnr, 4.16, De calopo ; 18, De capra... ; 87, De panthera, e 5.46, De fulica, si ha invece: "secando", "venatores aut viatores", "recondit se in spelunca sua", "intelligibile et prudentissimum". 
54. Per quello che concerne le locuzioni su castoro e caladrio, BIs riporta : "ostendit" e "interius femur curat caliginem oculorum" ; B : "demonstrat" e "interius fimus curat caliginem oculorum" ; e Ldnr, 4.14, De castoribus... : "ostendit", e 5.24, De caladrio: "interior femoris caliginem aufert ab oculis". Interessante in particolare la confusione fra il canonico elemento medico "fimus" con quello, più particolare - ed evidentemente derivato da una cattiva lettura del testo fonte -, di "femur".

55. In B: "De isto animali Hieremias propheta dicit: et asida in celo cognovit tempus suum"; e Ldnr, 5.110, De strutione: "Unde de ipsa ave Ieremias propheta dicit : assida in celo cognovit tempus suum". Il testo biblioco è ricavato dal Libro di Geremia, 8.7.

56. In tal senso si confrontino ad esempio il materiale ricavato dal Physiologus in Ldnr, 5.110, De strutione, e quello riportato nell'analogo passaggio della versio BIs . Per il testo delle due versioni, cf. infra, § Tabella 2.

57. Su tutto ciò e per l'analisi di come Tommaso usa le opere antologiche, cf. CIPRIANI, La place, 2014 : vol. 2, 52, 78-81, 92-93, 97-98, 100-114, 127-147, 164-166, 215-217, etc.

58. I termini e le locuzioni condivisi fra $L d n r, 7.19$, De cethe, e $Y$ sono: "anchoras", "falsa ignes accendunt" / "accendunt super eum ignem", "demergitur" / "demergit" ; per quanto riguarda invece Y, B e BIs si ha invece : "palos", "coquendum" / "coquant" / "quoquant" / "cocunt" e "mergit".

59. Ldnr, 6.43, De serra maiori, riporta : "pennasque habens latissimas et alas immanes" ; in $Y$ si trova : "alas habens longas"; e in B, A e BIs si ha invece : "pennas habens immanes".

60. Ldnr, Prologus: "doctor incomparabilis Augustinus [...] Galienus et Platearius preclari auctores in phisica sunt qui de natura corporis humani, arborum et herbarum virtutes medicine usui congruentes, plane distingunt [...] Adelmum quoque philosophum qui et si pauca tamen bona valde conscripsit".

61. Ldnr, Prologus : "et Physiologum compendiosum satis et utilem locis diversis inserui".

62. I cataloghi attribuiscono questo manoscritto al primo quarto del XIV sec., ma - in una conversazione privata del 29 / $10 / 2018$ - il Dr. Thomas Falmagne ha rettificato tale informazione : secondo la sua perizia, la stesura del codice si può infatti collocare nell'ultimo terzo del XIII sec. fra gli attuali Nord Francia e Belgio (si ringrazia il Dr. Falmagne per il prezioso aiuto e gli utili consigli).

63. Per alcuni esempi di queste abbreviazioni, cf. ms. Bonn, Universitätsbibliothek, S $487: 24 \mathrm{v}$, $25 \mathrm{r}$ e $38 \mathrm{v}$.

64. Per riferimenti a Ldnr, 5.117, De huppupa, cf. supra, § il Physiologus nel Liber de natura rerum.

65. La citazione "Physiologus" è ad esempio corretta nei manoscritti : Bonn, U.B., S 487 ; Stuttgart, Landesbibliothek, Cod. med. et phys. fol. 30 ; Brugge, Stadtbibliothek, 410 ; e Wrocław, Biblioteka uniwersytecka, Rehdig. 174 (per usare la terminologia ancora provvisioria - ma che rende bene l'idea -, i primi due codici sono rappresentanti della famiglia $\alpha$, fase Thomas I.a e riportano il marker di citazione abbreviato; il ms. belga e quello polacco sono invece rappresentanti della famiglia $\beta$, ma, rispettivamente, delle fasi Thomas II.b.1 e Thomas II.c del Liber: il ms. di Brugge sbroglia correttamente tale sigla, mentre il ms. polacco, come i codici tedeschi di famiglia $\alpha$, mantiene la sigla abbreviata). Quanto all'errato rimando "phylosophus", si ha nei manoscritti : London, B.L., Arundel 298, e Valenciennes, Bibliothèque municipale, 320 (che sono, rispettivamente, rappresentanti della famiglia $\alpha$, fase Thomas I.a, e della famiglia $\beta$, fase Thomas II.c, del Liber). Si può infine considerare "parzialmente corretta" la citazione nel ms. London, B.L., Harley 3717 : sebbene tale codice riporti inizialmente la dicitura "phylosophus", in un secondo momento la corregge tuttavia in "Physiologus" (questo noto codice appartiene alla famiglia $\beta$, ma è comunque molto vicino - nel suo testo "di base" - alla famiglia $\alpha$ e testimonia la costante attività editoriale a cui il Ldnr è stato soggetto fin da subito. Esso infatti riporta tre fasi di sviluppo del Ldnr, ovvero i momenti Thomas I.a, - dopo numerose correzioni e inserimenti Thomas I.b, e - dopo ulteriori aggiunte e rimaneggiati - Thomas II.a e, ameno parzialmente, Thomas II.c).

66. Per la segnalazione di questi elementi si ringrazia nuovamente la Dott.ssa Kuhry, che ha fornito anche alcune utili spiegazioni in merito (in particolare in una discussione privata del 
20/12/2018). Fra le caratteristiche del Physiologus di Montecassino si deve inoltre aggiungere che esso difetta del capitolo fulica e amos, solitamente presenti nella versio $B$.

67. Per la versio $A$, è stata usata la precaria edizione in CAHIER, MARTIN; dove ritenuto necessario si indicano pertanto le principali varianti del ms. di Rouen. Per quello che concerne la Versio $B$, il testo riportato è quello di Carmody; viste le problematiche legate a tale edizione - inserimento del capitolo Lacerta e di sezioni da BIs, divisione di Mustela e Aspis,... -, per i capitoli mancanti è stato usato il testo $B$ del ms. di Montecassino (su tutta la questione, cf. BAXTER, Bestiaries : 30, n. 3; e KUHRY, « Les chapitres sur les poissons », $2019:$ n. 27). Per una panoramica su edizioni e testi usati nei confronti, cf. supra. Nota: Le presenti trascrizioni sono state realizzate solo per confronto testuale, e, di conseguenza, non è stato messa in atto su di essi nessuna procedura filologica.

68. Per le edizioni e le versioni usate nei confronti, cf. supra.

69. Rouen, Bibliothèque Municipale, $638,232 \mathrm{v}$ : om. et.

70. Rouen, B.M., 638 , f. $232 \mathrm{v}$ : om. ... eum, ille videns se iam evadere non posse, erigit ... .

71. Rouen, B.M., 638, f. 232v : referare.

72. Rouen, B.M., 638, f. $232 \mathrm{v}$ : prosternere.

73. Rouen, B.M., 638, f. 232v : liberare se.

74. Rouen, B.M., 638, f. 232v : referare.

75. Rouen, B.M., 638, f. 232v : prosternere.

76. Rouen, B.M., 638, f. 232v : prosternere.

77. La parola è estremamente rovinata e difficle da interpretare.

78. Rouen, B.M., 638, f. $237 \mathrm{v}$ : et in die ex numero horarum... .

79. Rouen, B.M., 638, f. $237 \mathrm{v}$ : formam.

80. Rouen, B.M., 638, f. $232 \mathrm{v}$ : cumprehenditur.

81. Rouen, B.M., 638, f. $232 \mathrm{v}$ : om. ... et exhibetur in palatio regis ... .

82. Cf. supra, n. 70: anche in questo caso Carmody usa infatti una copia BIs per emendare i suoi codici lacunosi.

83. Rouen, B.M., 638 , f. $234 \mathrm{v}$ : eliopoleos.

84. Rouen, B.M., 638, f. $234 \mathrm{v}$ : om. ... tercia die veniens sacsecundos, invenit eam stato suo integram atque perfectam seneam valefacientem sacerdoti ... .

85. Parole incomprensibili.

86. Rouen, B.M., 638, f. 239r : excrivelat.

87. Rouen, B.M., 638, f. 238v : camelo et ideo grece camelon dicitur.

88. Rouen, B.M., 638 , f. $238 \mathrm{v}$ : austrum.

89. Rouen, B.M., 638, f. 239r : iulium.

90. Rouen, B.M., 638, f. 239r : om. pullos suos.

91. Rouen, B.M., 638, f. 232v : om. ...nave. Ubi currerit contendendum contra... .

92. Rouen, B.M., 638, f. 238r : uno.

93. Rouen, B.M., 638, f. 238r : subito expergefactus.

94. Rouen, B.M., 638, f. 238r : exit.

95. Aggiunto sopra : evigilatus.

96. Cf. supra, n. 70. 


\section{RIASSUNTI}

Nel Prologus al suo Liber de natura rerum (1225 ca.-1260 ca.), il domenicano Tommaso di Cantimpré elenca le 15 fonti principali del suo lavoro. Al penultimo posto di tale lista, egli pone il Physiologus, descrivendolo come come un'auctoritas "abbastanza succinta e utile in diverse occasioni". Partendo da questa indicazione, il presente articolo indaga quindi due aspetti di questo rapporto, ovvero come e quanto il trattatello di origine alessandrina è effettivamente usato nell'enciclopedia domenicana, e quale versione di tale fonte era sul tavolo di lavoro tommasiano durante la stesura del Liber.

In the Prologus to his Liber de natura rerum (1225 ca.-1260 ca.), the Dominican Thomas of Cantimpré lists the 15 sources he used most during the writing of the encyclopedia. In the penultimate place on this list, he puts the Physiologus and describes it as an auctoritas "quite succinct and useful on several occasions". Starting from this indication, the present article investigates therefore two aspects of this relationship. First, how and how much the Alexandrian treatise is actually used in the Dominican encyclopedia. Second, what version of this didactic work was on Thomas' desk during the drafting of the Liber.

Dans le Prologue de son Liber de natura rerum (1225 ca.-1260 ca.), le dominicain Thomas de Cantimpré énumère les quinze sources qu'il a le plus utilisées lors de la rédaction de l'encyclopédie. À l'avant-dernière place de cette liste, il place le Physiologus qu'il décrit comme une auctoritas " assez succincte, et utile à plusieurs reprises ». A partir de cette indication, le présent article étudie deux aspects de cette relation. D'abord, comment et dans quelle mesure le traité alexandrin est effectivement utilisé dans l'encyclopédie dominicaine ; en second lieu, quelle version de cette œuvre didactique se trouvait sur le bureau de Thomas lors de la rédaction du Liber.

\section{INDICE}

Mots-clés : Thomas de Cantimpré, Liber de natura rerum, Physiologus, encyclopedisme médiéval, études médiévales

Parole chiave : Tommaso di Cantimpré, Liber de natura rerum, Physiologus, enciclopedismo medievale, studi medievali

Keywords : Thomas of Cantimpré, Liber de natura rerum, Physiologus, Medieval encyclopedism, Medieval studies

\section{AUTORE}

\section{MATTIA CIPRIANI}

Mattia Cipriani est Docteur (2014) en "Histoire, textes et documents" de l'Ecole Pratique des Hautes Etudes (Paris) et en "Antichità, Medioevo e Rinascimento" de la Scuola Normale Superiore (Pisa), avec une thèse obtenue en co-tutelle et intitulée La place de Thomas de Cantimpré dans l'encyclopédisme médiéval : les sources du Liber de natura rerum. Il est actuellement titulaire d'une Bourse de Recherche "Alexander von Humboldt" à la Freie Universität (Berlin). Ses recherches se concentrent principalement sur l'encyclopédisme médiéval, et sur la transmission des textes et des idées naturalistes, en particulier zoologiques. 